\title{
Numerical Simulation of Transient Cavitation Characteristics of Valve-Controlled Liquid-Filled Hydrodynamic Coupling
}

Hongwei Cui ( $\nabla$ cuihongwei@tyut.edu.cn )

Taiyuan University of Technology https://orcid.org/0000-0002-3306-6298

Jiahua Zhang

Taiyuan University of Technology

Guoqiang Wang

Taiyuan University of Technology

Original Article

Keywords: Valve-controlled liquid-filled hydrodynamic coupling, cavitation, scale-resolving simulation, CFX

Posted Date: September 22nd, 2020

DOl: https://doi.org/10.21203/rs.3.rs-78889/v1

License: (c) (i) This work is licensed under a Creative Commons Attribution 4.0 International License. Read Full License 


\title{
Numerical Simulation of Transient Cavitation Characteristics of Valve-Controlled Liquid-Filled Hydrodynamic Coupling
}

\author{
Hongwei Cui ${ }^{1,2,3, *}$, Jiahua Zhang ${ }^{1}$, Guoqiang Wang ${ }^{1}$
}

\begin{abstract}
In high-power impeller industries, valve-controlled liquid-filled hydrodynamic couplings are widely used in the soft startup of heavy-duty scraper conveyors for mining. However, the water circulation speed in internal flow fields is higher at lower speed ratios, making the hydrodynamic couplings prone to severe cavitation, which further results in severe performance degradation, noise, vibration, or even erosion failure. Meanwhile, because a hydrodynamic coupling is a piece of closed-loop multicomponent turbomachinery, internal transient cavitation flow behavior cannot be easily controlled. To reasonably predict the characteristics of cavitation and its influence on the working performance of the hydrodynamic coupling, a high-quality structured mesh model of the internal flow field for an impeller was established. Considering the periodic structural characteristics of the impeller, a scale-resolving simulation turbulence model was combined with a Rayleigh-Plesset cavitation model to establish a single-cycle hydrodynamic coupling calculation model. The cavitation distribution characteristics and torque transmission of the flow field under different working conditions were obtained, and the effect of cavitation on the soft startup performance was analyzed. The results demonstrated that cavitation in the hydrodynamic coupling mainly occurred under low speed ratios. The degree of cavitation decreased as speed ratio increased. The worst-case scenario for cavitation occurred when the speed ratio was zero. Most of the cavitation bubbles were generated at the tip of the blades, resulting in unstable variation in torque characteristics and deterioration of the working performance of the hydrodynamic coupling. The analysis reveals that the cavitation process in the impeller is highly unstable and periodic, and the cavitation development near the tip of the blades occurs in four stages: birth, growth, separation, and disintegration. The generated steam accumulates in the inner ring of the impeller. Therefore, a method for accurately predicting the cavitation characteristics of hydrodynamic couplings based on high-precision technology is proposed, and a theoretical basis for coupling design and cavitation suppression technology is provided.
\end{abstract}

Key words: Valve-controlled liquid-filled hydrodynamic coupling, cavitation, scale-resolving simulation, CFX

\section{Introduction}

Coal resources are important foundations for human survival and development and a main energy source used by humans since the 18th century. Coal has been and will continue to be an indispensable energy source for human productivity and life. Therefore, efficient and safe mining equipment plays a vital role in coal mining and utilization.

Scraper conveyors often encounter harsh working conditions, such as excessively hard coal walls, sudden changes in coal production, stagnation of scraper chains, and unbalanced loads. These conditions can cause unexpected shutdowns, affect production efficiency, and affect the reliability and service life of the motor and scraper conveyor. Commonly used transmission devices in mines include valve-controlled liquid-filled hydrodynamic couplings, controlled start transmission, and frequency conversion drive devices. Compared with other transmission methods, valve-controlled liquid-filled hydrodynamic couplings use water as the working medium. The amount of liquid in the hydrodynamic coupling is varied via a hydraulic valve; speed regulation and soft starting of the load are then realized. As a commonly used soft start device on conveyors, this hydrodynamic coupling exhibits the advantages of a large starting torque coefficient, flexible transmission, simple structure, reliable performance, low equipment investment, and low maintenance cost[1].

With the rapid development of computing power and various commercial finite-element software packages, the application of computational fluid dynamics (CFD) technology has become crucial to solve the problem of fluid calculation. To study hydraulic transmission, several researchers have conducted numerical computations for various hydraulic components based on CFD technology.

Yan et al.[2] established torque converter models with different unloading hole parameters using CFD technology to study the effect of these parameters on the axial force of a torque converter. Liu et al.[3] compared the accuracy of predicting the flow field characteristics of the torque converter using Reynolds-averaged Navier-Stokes and scale-resolving simulations and studied a method for predicting the characteristics of the torque converter using scale

\footnotetext{
*Correspondence: cuihongwei@tyut.edu.cn

${ }^{1}$ College of Mechanical Engineering, Taiyuan University of Technology, Taiyuan 030024, China

Full list of author information is available at the end of the article
} 
analysis simulations. Wei et al.[4] conducted a flow field simulation to investigate the action process of a spoiler inside cascades under low-oil-charging-ratio operating conditions and provided a theoretical foundation for spoilers inside a hydrodynamic retarder. Ma et al.[5] used CFD technology to predict the working characteristics of a torque converter with an adjustable guide vane and analyzed the flow field characteristics.

Cavitation is a transient phase change phenomenon. Vapor bubbles occur, grow, and collapse in liquids with variations in the local pressure. This is a common issue in fluid machinery. To face complex coal conditions underground, mining equipment with high power that can sustain high loads are being developed. This has increased the demand for the soft start and stable transmission capabilities of the hydrodynamic coupling. A higher power density results in a higher circulation velocity and lower local pressure in the internal flow field. Simultaneously, because the working medium of the high-power hydrodynamic coupling for mining is water, a large amount of dissolved gas and undissolved microbubbles are present in the medium. Therefore, cavitation can easily occur, particularly on the blade surface, leading to unstable transmission and reduced power, thus reducing the life of the impeller.

At present, research on the cavitation phenomenon of the hydraulic transmission device primarily entails the torque converter. Anderson et al.[6] investigated cavitation signatures under the stall condition in an automotive torque converter using a microwave telemetry technique. Liu et al.[7-8] studied the influence of the stator blade shape on the cavitation process of a hydraulic torque converter and found that cavitation is directly related to the internal mass flow rate. Robinette et al.[9-11] investigated the effects of torque converter design and operating conditions on the onset of cavitation during vehicle launch using a nearfield acoustical technique. From their numerical results, Dong et al.[12] determined that the cavitation on the stator leading edge grew in size with increasing pump speed, resulting in severe performance degradation in the torque converter. Zhao[13] used the full channel transient CFD calculation model to simulate the mechanism of bubble breakup in a hydraulic torque converter by implanting bubbles in it, and they calculated the high incidence area of bubble breakdown. Watanabe et al.[14-16] established a cavitation observation model based on a transparent plastic torque converter. A high-speed camera was used to observe the cavitation in the torque converter, which was combined with dynamic torque testing to confirm that the cavitation process produced high-frequency torsional vibration. Kang[17] and Dong[18] studied the flow structure and cavitation phenomena in a hydraulic retarder. In addition, several important results have been obtained from research on hydrofoil cavitation[19-21].

Because hydraulic transmission machinery is a closed multi-impeller rotating machine, the internal two-phase flow phenomenon cannot be easily observed[22]. The current research results are mainly on the torque characteristics and two-phase flow field under part filling conditions. Studies have been conducted on the cavitation of hydrodynamic coupling[23-25]. In addition, theoretical speculations suggest that, owing to the particularity of the working medium and working conditions of the mining high-power valve-controlled liquid-filled hydrodynamic coupling, the cavitation phenomenon has a greater impact on the working characteristics of the coupling under the condition of an impeller high-speed difference. Therefore, this study aims to analyze the occurrence and development of cavitation in the flow field of high-power hydrodynamic couplings as well as to examine their external characteristics. This is of great significance for improving the accuracy of the prediction of hydrodynamic coupling characteristics and for improving performance and durability.

The research object in this study was a high-power mine-adjustable double-chamber hydrodynamic coupling with a circulation circle outer diameter of $575 \mathrm{~mm}$. A single-channel calculation model of the impeller flow field on the output side was established. A SBES calculation model was used to study the effect of cavitation on the performance of the fluid coupling. The development of the torque characteristics and cavitation distribution of the fluid coupling under closed working conditions was analyzed. The results provide a high-precision research method for the cavitation characteristics of fluid couplings; they also provide a reliable theoretical basis for the optimization of the structure of fluid couplings.

\section{Numerical Simulation}

\subsection{Geometric and mesh model}

The structure and working principle of the valve-controlled liquid-filled hydrodynamic coupling are shown in Figure 1. The speed-adjusting double-chamber hydrodynamic coupling with the outer diameter $\mathrm{D}=575 \mathrm{~mm}$ was considered as the analysis model. The numbers of pump wheels and turbine blades were 46 and 45 , respectively. Because the two pairs of impellers of this coupling had symmetrical structures, the flow field of the output impeller was used as the calculation model. The speed ratio of the hydrodynamic coupling was defined as $i=n_{T} / n_{P}, n_{T}$ was the turbine rotation speed and $n_{P}$ was the pump rotation speed. To describe the spatial position of the impeller blades accurately, the surfaces of the different side blades of the pump and turbine were defined according to the impeller rotation direction. The parameters of the coupling impeller are listed in Table 1, and the process of establishing the flow field model is shown in Figure 2. 


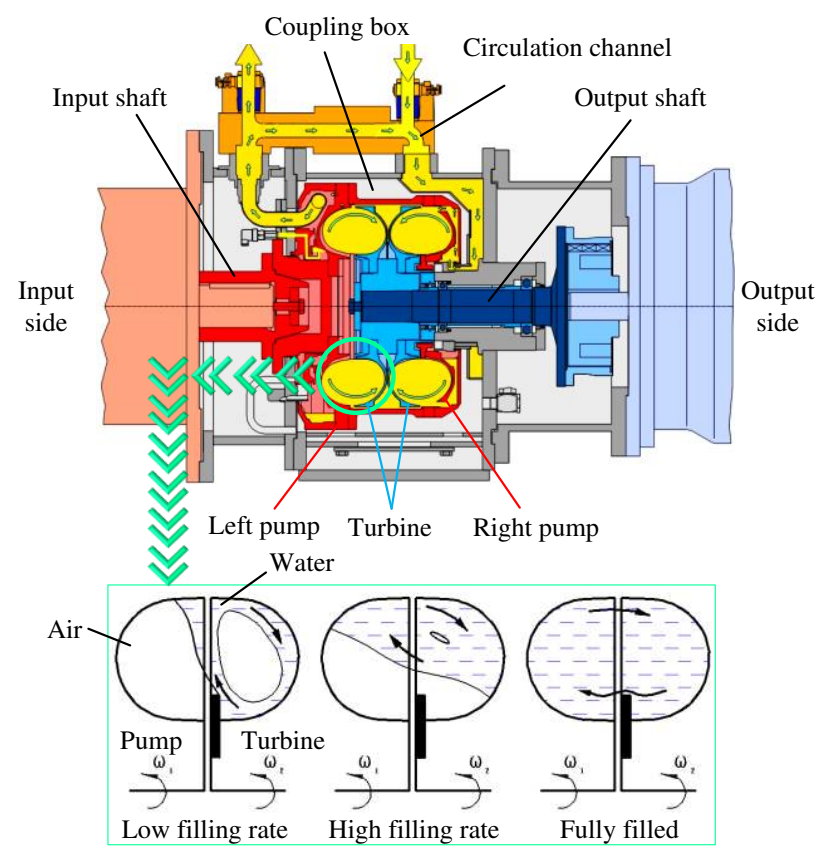

Figure 1. Structure and working principle of hydrodynamic coupling

Table 1. Structure parameters of the coupling impeller

\begin{tabular}{cc}
\hline Parameters & Value \\
\hline Circular circle outer diameter, $D(\mathrm{~mm})$ & 575 \\
Circular circle inner diameter, $d(\mathrm{~mm})$ & 276 \\
Baffle diameter, $d_{\mathrm{B}}(\mathrm{mm})$ & 320 \\
Baffle thickness, $h_{\mathrm{B}}(\mathrm{mm})$ & 5 \\
Impeller material & ZL101A \\
Rotation speed of pump, $n_{\mathrm{P}}(\mathrm{r} / \mathrm{min})$ & 1475 \\
Number of pump blades, $B N_{\mathrm{P}}$ & 46 \\
Number of turbine blades, $B N_{\mathrm{T}}$ & 45 \\
Minimum blade thickness, $h(\mathrm{~mm})$ & 3 \\
\hline
\end{tabular}

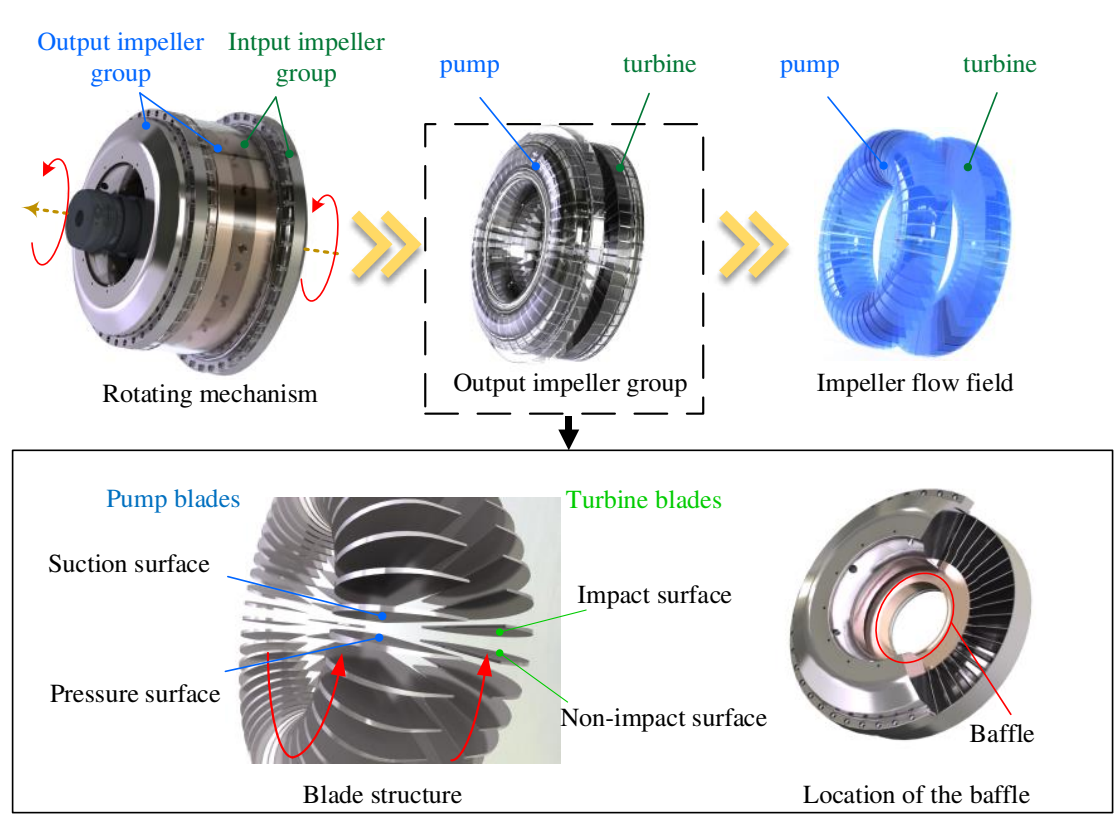

Figure 2. Hydrodynamic coupling impeller and flow field structure 
To improve the computation efficiency and obtain a high flow field mesh density, a single flow channel calculation model of $1 / x$ (where $x$ is the number of impeller blades) was obtained by utilizing the cyclically symmetric structural characteristics of the inner flow field. The structured hexahedral grid in ICEM CFD was used to discretize the flow field model of a single channel of a fluid coupling. Moreover, o-division and mesh refinement were performed at the circle of curvature and the blade wall surface to improve the computational efficiency and mesh quality. This was because the three-dimensional circulation of the flow field in the coupling was complicated, and the cavitation was distributed under extremely unsteady conditions. Therefore, a high-quality mesh was required to calculate the actual flow state and capture the transient cavitation flow behavior. The process of establishing the single-channel mesh model is shown in Figure 3.

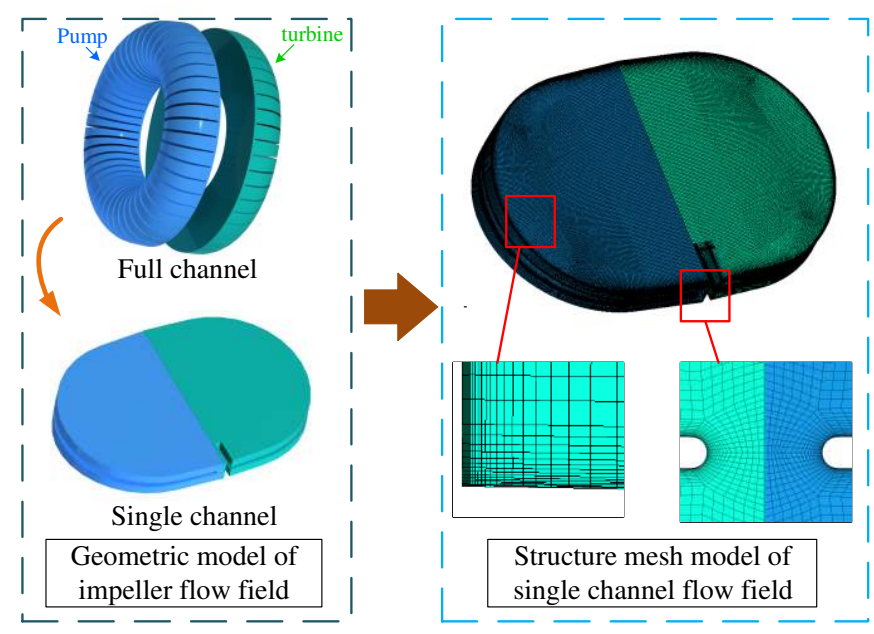

Figure 3. Single-channel structured grid construction process

The accuracy and efficiency of the solution are directly affected by the quality and quantity of the mesh. In theory, a higher number of grids produce better calculation accuracy, but more grids require greater computing resources. Therefore, an appropriate mesh density should be determined to achieve an appropriate balance between accuracy and computational cost. The calculated torque change rate $f(\mathrm{n})$ of the mesh with different grid densities is

$$
f(\mathrm{n})=\frac{T(\mathrm{n}-1)-T(\mathrm{n})}{T(\mathrm{n})}
$$

where $T(\mathrm{n})$ is the computation result under the current density mesh, and $T(\mathrm{n}-1)$ is the computation result under the previous mesh with lower density. When the change rate of the calculation result between the two meshes with different densities is less than $3 \%$, the influence of the current mesh density on the calculation result is acceptable-that is, the calculation result is independent of the grid. Mesh independence tests were performed on seven models with different grid resolutions. The results are listed in Table 2 and shown in Figure 4.

Table 2. Structural mesh independence analysis results

\begin{tabular}{ccccc}
\hline $\begin{array}{c}\text { Number of grids in pump } \\
\text { flow field }\end{array}$ & $\begin{array}{c}\text { Global size setting } \\
(\mathrm{mm})\end{array}$ & $\begin{array}{c}\text { Time consumption } \\
(\mathrm{min})\end{array}$ & Pump wheel torque $(\mathrm{N} \cdot \mathrm{m})$ & $f(\mathrm{n})$ pump \\
\hline 83,036 & 3.5 & 6 & 286.377 & $3.24 \%$ \\
121,512 & 3 & 10 & 277.062 & $2.96 \%$ \\
163,254 & 2.5 & 16 & 269.734 & $2.66 \%$ \\
248,045 & 2 & 30 & 261.862 & $1.59 \%$ \\
364,704 & 1.7 & 50 & 258.997 & $0.89 \%$ \\
679,386 & 1.3 & 89 & 257.700 & $0.34 \%$ \\
$1,406,380$ & 1 & 140 & 256.837 & \\
\hline
\end{tabular}




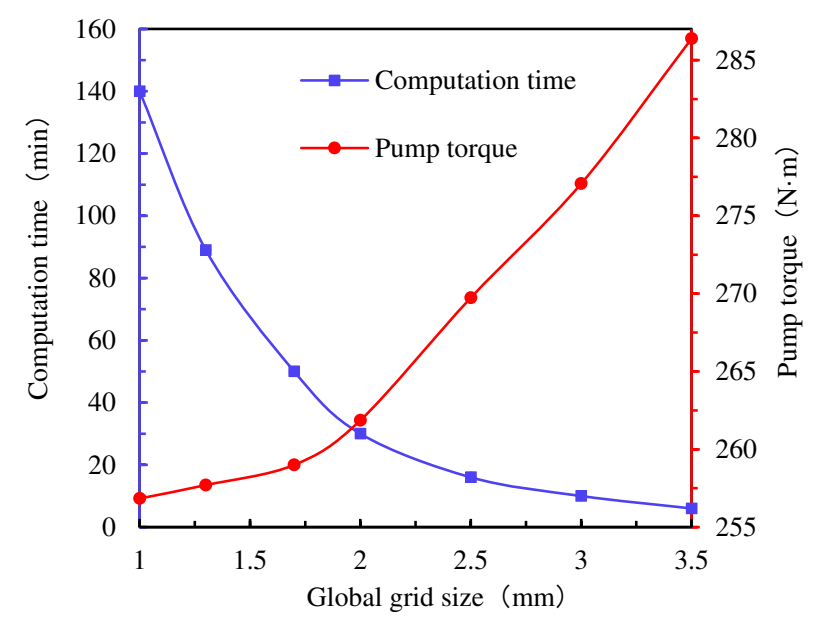

Figure 4. Analysis results of grid independence test

When the global size of the mesh is less than $1.7 \mathrm{~mm}$, the torque change generated by further increasing the number of grids is less than $2 \%$ and the model is considered to be mesh-independent. Considering the calculation efficiency and precision comprehensively, the global grid size is selected to be $1.7 \mathrm{~mm}$. The grids number of the turbine flow field is 948,230 , and the grids number of the turbine flow field is 1,157,138.

To ensure the accuracy of the boundary layer flow field computation, the minimum boundary layer size was set to 0.01 $\mathrm{mm}$, which ensured that the minimum $y+$ value around the blade was less than 10 . The grid thickness growth rate was set to 1.15 . The $y+$ of the mesh model was verified under the $i=0$ condition with a high water circulation velocity. Figure 5 shows the distribution of $y+$ at the wall of the flow channel and blade. The maximum $y+<6$ can satisfy the computational requirements.

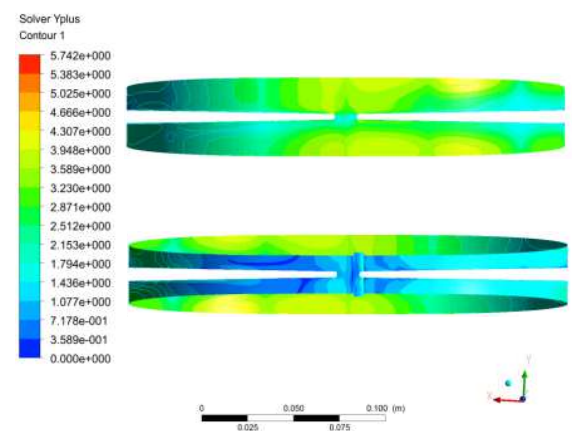

Distribution of $y+$ at the wall

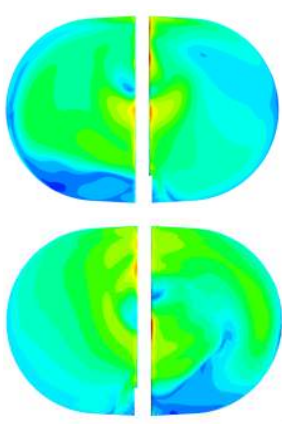

Distribution of $y+$ at the blade

Figure 5. Computation result of $y+$

\subsection{Multiphase model}

In this study, the multiphase flow field caused by cavitation in the completely filled liquid flow field was obtained. In addition to the general set of mass conservation equations, the mass exchange between liquid and non-condensable vapor is governed by the following transport equation:

$$
\frac{\delta}{\delta t}\left(f_{l} \rho_{l}\right)+\frac{\delta}{\delta x_{j}}\left(f_{l} \rho_{l} v_{j}\right)=\dot{m}
$$

The key to solving the cavitation problem is the determination of the interphase mass transfer rate, i.e., cavitation rate, which is driven by the difference between local pressure and vapor pressure[26]. Assuming that no interphase slip or heat transfer exists between the liquid and vapor, the radius of a spherical vapor bubble can be described by the RayleighPlesset equation in its first-order approximation form as follows: 


$$
\frac{d R_{B}}{d t}=\sqrt{\frac{2}{3} \frac{p_{v}-p}{\rho_{t}}}
$$

Then, the cavitation rate during vaporization can be given as

$$
\dot{m}=\frac{3 f_{v} p_{v}}{R_{B}} \sqrt{\frac{2}{3} \frac{p_{v}-p}{\rho_{l}}}
$$

Because the nucleation site density decreases when the vapor volume fraction increases, the vapor volume fraction $f_{v}$ is replaced by $f_{\text {nuc }}\left(1-f_{v}\right)$ to yield the following:

$$
\dot{m}^{-}=-F_{\text {vap }} \frac{3 f_{\text {nuc }}\left(1-f_{v}\right) \rho_{v}}{R_{B}} \sqrt{\frac{2}{3} \frac{p_{v}-p}{\rho_{l}}}
$$

When the partial pressure exceeds the vapor condensation pressure, the mass transfer rate becomes

$$
\dot{m}^{+}=F_{\text {cond }} \frac{3 f_{v} \rho_{v}}{R_{B}} \sqrt{\frac{2}{3} \frac{p-p_{v}}{\rho_{l}}}
$$

Because the condensation process is generally much slower than vaporization, different empirical factors are assumed as follows: $F_{\text {vap }}=50, F_{\text {cond }}=0.01, f_{\text {nuc }}=5 \mathrm{e}-4$, and $R_{\mathrm{B}}=1 \mathrm{e}-6 \mathrm{~m}$.

A homogeneous multiphase condition is also assumed to simplify the model; thus, the liquid and vapor share the same velocity and turbulence profiles. The mixture of fluid and vapor is treated as a pseudofluid whose density $\rho_{\mathrm{m}}$ and dynamic viscosity $\mu_{\mathrm{m}}$ are defined as follows:

$$
\begin{gathered}
\rho_{m}=\left(1-f_{v}\right) p_{t}+f_{v} \rho_{v} \\
\mu_{m}=\left(1-f_{v}\right) \mu_{l}+f_{v} \mu_{v}
\end{gathered}
$$

\subsection{Simulation analysis}

First, the upwind steady-state model was used to determine the flow field characteristics of the fluid coupling without cavitation. The high-resolution convection scheme was then used to perform steady-state computations to provide accurate flow field conditions. Based on the results of the noncavitation model, a high-resolution scheme was used to simulate the steady-state cavitation behavior. Finally, with the steady-state cavitation output as the initial condition, a transient CFD cavitation model was established to simulate the dynamic cavitation process in the internal flow field.

For the interface between the flow field and impeller wall surface and blade wall surface, the nonslip wall surface treatment was adopted, while the wall surface roughness was neglected. In the steady-state computation stage, the stage interface model was used to exchange data between the pump-turbine flow field interface. In the transient computation stage, the transient rotor-stator interface model was used to capture more transient flow characteristics. The corresponding CFD multistep solution model settings are listed in Table 3.

Table 3. CFD model settings

\begin{tabular}{ccccc}
\hline Analysis step & I & II & III & IV \\
\hline Analysis type & Steady state & Steady state & Steady state & Transient \\
Interface model & Stage & Stage & Stage & Transient rotor-stator \\
Cavitation model & None & None & Rayleigh-Plesset & Rayleigh-Plesset \\
Turbulence model & SST & SST & SST & DES \\
Advection scheme & Upwind & High resolution & High resolution & High resolution
\end{tabular}




\begin{tabular}{|c|c|c|c|}
\hline Time step & $1 \mathrm{e}-3 \mathrm{~s}$ & Auto timescale & Auto timescale \\
\hline Convergence target & RMS 1e-4 & RMS $1 \mathrm{e}-5$ & RMS 1e-5 \\
\hline Fluid properties & & $\rho_{\text {water }}=970 \mathrm{kgm}^{-3}, \mu_{\text {water }}=8.9 \mathrm{e}-4$ Pas & \\
\hline Vapor properties & & $\rho_{\text {vapor }}=2.3 \mathrm{e}-2 \mathrm{kgm}^{-3}, \mu_{\text {vapor }}=9.8 \mathrm{e}-6$ Pas & \\
\hline Pump status & & Fixed at $1475 \mathrm{rpm}$ & \\
\hline Turbine status & & Varied from $0 \sim 1465.2 \mathrm{rpm}$ & \\
\hline Boundary details & & No slip and smooth wall & \\
\hline Heat transfer model & & $50^{\circ} \mathrm{C}$ isothermal & \\
\hline Saturation pressure & & $12333.43 \mathrm{~Pa}$ & \\
\hline
\end{tabular}

To obtain accurate cavitation characteristics and corresponding flow field characteristics, the SST SBES DSL model in the scale-resolving simulation is used in transient computations. Compared with the DES, this model features a considerably improved shielding function to protect RANS boundary layers from the impact of the grid-dependent term; further, this model can automatically switch between existing RANS and LES models[27].

The shielding function developed can be used in the following manner for achieving a blending on the stress level between RANS and LES formulations:

$$
\tau_{i j}^{S B E S}=f_{S D E S} \tau_{i j}^{R A N S}+\left(1-f_{S D E S}\right) \tau_{i j}^{L E S}
$$

where $\tau_{i j}^{R A N S}$ is the RANS portion and $\tau_{i j}^{L E S}$ is the LES portion of the modeled stress tensor. In cases where both models are based on eddy viscosity concepts, the formulation can be simplified as follows:

$$
v_{t}^{S B E S}=f_{S D E S} v_{t}^{R A N S}+\left(1-f_{S D E S}\right) v_{t}^{L E S}
$$

\section{Experimental Research}

A macro characteristic test was conducted, wherein a motor was used to provide power at the input end and load at the output end, to simulate the working conditions of the downhole fluid coupling. A pump station was used to control the inlet and outlet pressures of the valve control oil and working water, complete the startup of the coupling, and test the macroscopic characteristics of the hydrodynamic coupling at different speed ratios. The rotation speed and torque sensors were used to obtain the dynamic hydraulic performance of the coupling. According to the comprehensive analysis results of the torque transmission characteristic computation data and test data, the prediction accuracy of the torque characteristic was verified. The macro characteristic test plan and parameter settings of the hydrodynamic coupling are shown in Figure 6 and listed in Table 4.

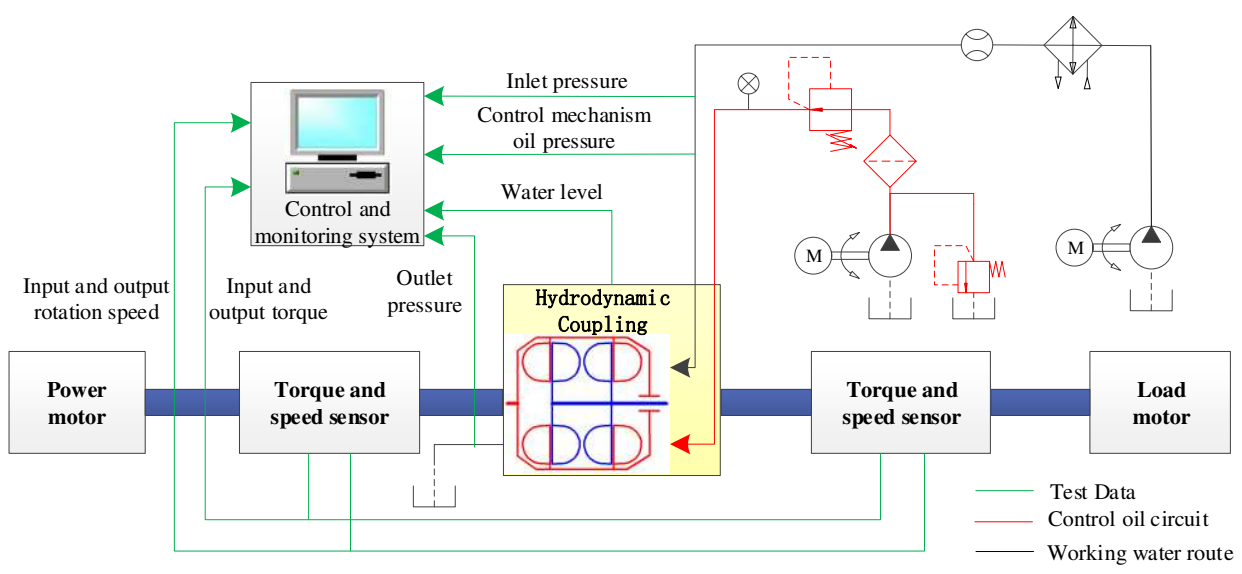

Figure 6. Macro characteristics test plan 
Table 4. Test device parameter setting

\begin{tabular}{cc|cc}
\hline \multicolumn{2}{c|}{ Main parameters of test bench } & \multicolumn{2}{c}{ Main parameters of hydrodynamic coupling } \\
\hline Power of power motor & $2500 \mathrm{~kW}$ & Rated power & $1200 \mathrm{~kW}$ \\
Rated input rotation speed & $1475 \mathrm{rpm}$ & Rated rotation speed of pump & $1475 \mathrm{rpm}$ \\
Power of dynamometer & $2500 \mathrm{~kW}$ & Water supply flow & $>240 \mathrm{~L} / \mathrm{m}$ \\
& & Water supply pressure & $>4-16 \mathrm{bar}$ \\
\hline
\end{tabular}

Data collection system: The test system data were collected by an efficiency meter industrial control computer. The main collection parameters were as follows: input torque, input speed, output torque, output speed, coupling liquid level pressure, coupling working chamber temperature, filling and discharging liquid valve action signal, and other data.

According to the test plan, a macro characteristic testbed was built, as shown in Figure 7. Carry out several repeated tests from starting and running to complete filling, draining, circulating and changing fluids. The working performance and reliability of the equipment were examined.

Test procedure: The drag motor was started at no load, drag motor was maintained at $1475 \mathrm{rpm}$, and coupling was filled with liquid. The coupling was then loaded until it reached the rated power and remained at the rated working conditions. After $8 \mathrm{~h}$ of operation, the coupling ran smoothly without abnormal noise. The input and output speed and torque data were collected and analyzed during the loading process.

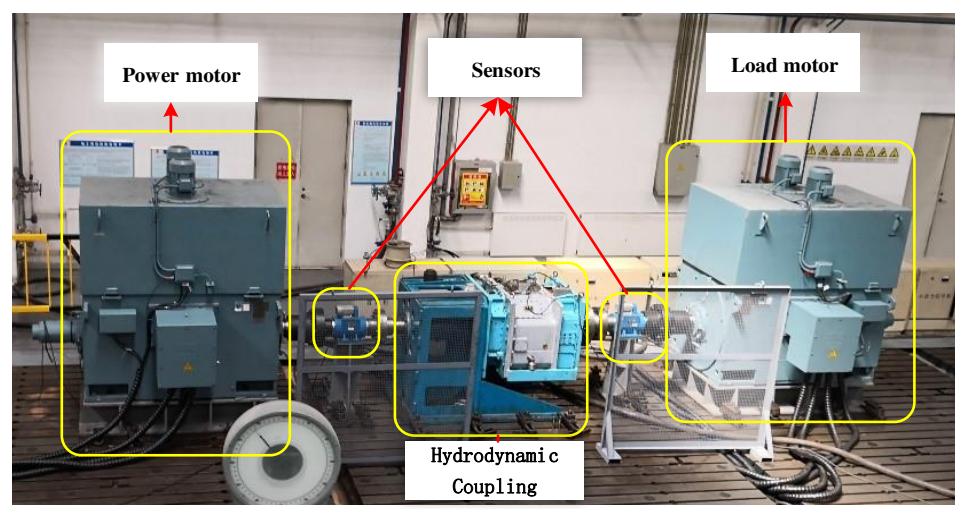

Figure 7. Macro characteristic test rig

\section{Results and Discussion}

\subsection{Characteristics of steady flow field}

According to the numerical analysis results of steady-state cavitation two-phase flow under fully filled working conditions, following the multicycle cavitation and steam accumulation processes in the flow field of the hydrodynamic coupling, a stable inner ring steam accumulation area was formed. The field resulted in a more stable circulation characteristic. The distribution characteristics of cavitation were analyzed at different speed ratios, combined with the liquid velocity and blade pressure distribution trends obtained before and after the cavitation computation model was opened at different speed ratios, which was required to realize complete filling. This analysis was then used to analyze the influence of cavitation on the flow field distribution characteristics.

\subsubsection{Cavitation distribution characteristics}

Transient CFD computation revealed that, in all the calculated speed ratio ranges, cavitation phenomena occurred at different degrees. The cavitation distribution characteristics at a $10 \%$ steam volume ratio and different speed ratios were compared, as shown in Figure 8. At low speed ratios, owing to the large rotational speed difference of the impellers and the high circulation velocity, severe cavitation occurred, and the gas phase area of the impeller was large. As the speed ratio increased, the cavitation in the flow channel gradually decreased, and the cavitation distribution in the pump wheel flow field was greater than that of the turbine. As the speed ratio increased, the cavitation in the turbine gradually disappeared. 
With a further increase in the speed ratio, when the difference between the speed of the pump wheel and the turbine was close to 0 , cavitation almost ceased to occur in the impeller, and the steam disappeared completely.

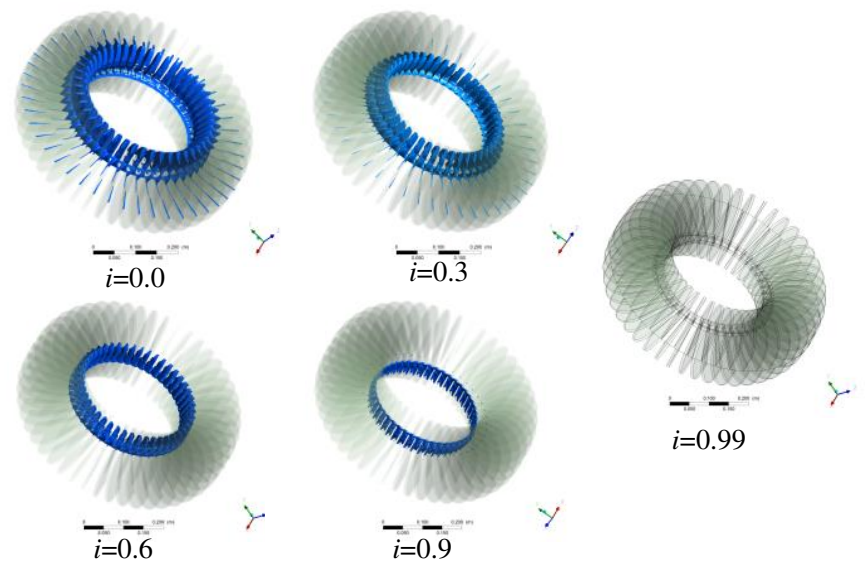

Figure 8. Steady-state cavitation distribution

\subsubsection{Velocity streamline distribution}

Figures 9(a) and (b) show the distribution characteristics of the flow field velocity streamlines when the cavitation computation model is turned off and on, respectively. Comparative analysis shows that the water-liquid circulation velocity gradually decreased as the speed ratio increased. Because the steam generated in the cavitation process accumulated in the inner ring of the impeller, the water-liquid circulation state changed, and the circulation velocity was lower than that without the cavitation model. With an increase in the speed ratio, the volume of the vapor accumulation zone decreased because of the decrease in the degree of water cavitation, and its influence on the state of water circulation and flow velocity also decreased.
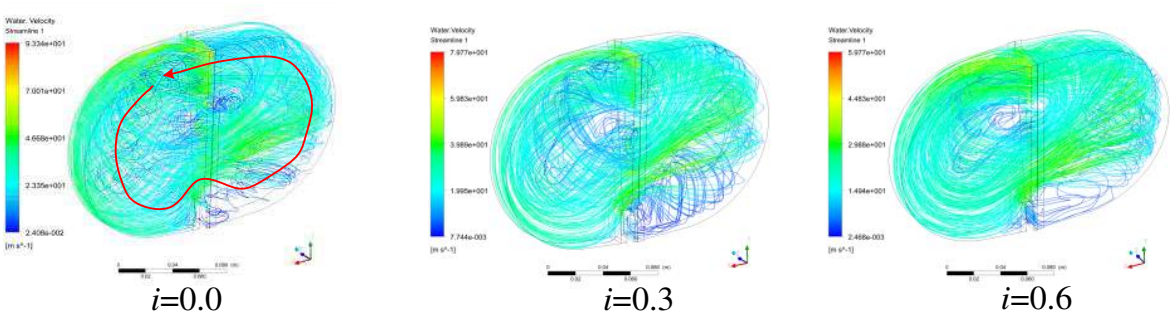

(a) Cavitation model is off
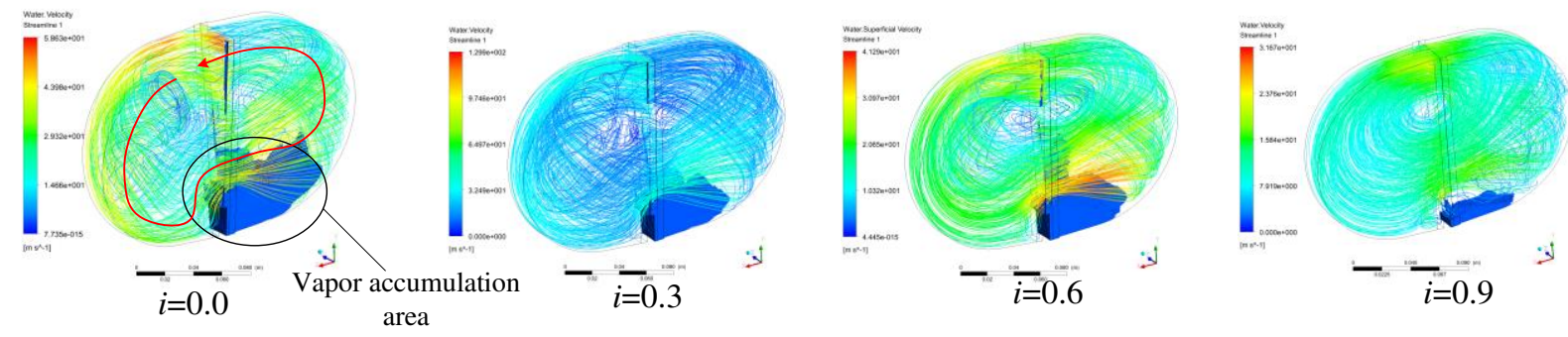

(b) Cavitation model is on

Figure 9. Velocity streamline distribution

\subsubsection{Pressure distribution of blade wall}

A comparative analysis of the effects of steam accumulation on the blade pressure field distribution under different steady-state cavitation simulation conditions is shown in Figure 10. The overall pressure distribution trends at the blade wall before and after opening the cavitation computation model were the same. Owing to the change in the circulation characteristics, the overall pressure distribution of the blade after cavitation was reduced. Simultaneously, because of the 
existence of the vapor accumulation area, the corresponding area generates low-pressure areas $\mathrm{A}$ and $\mathrm{B}$, and the pressure gradient of the blade was evident.

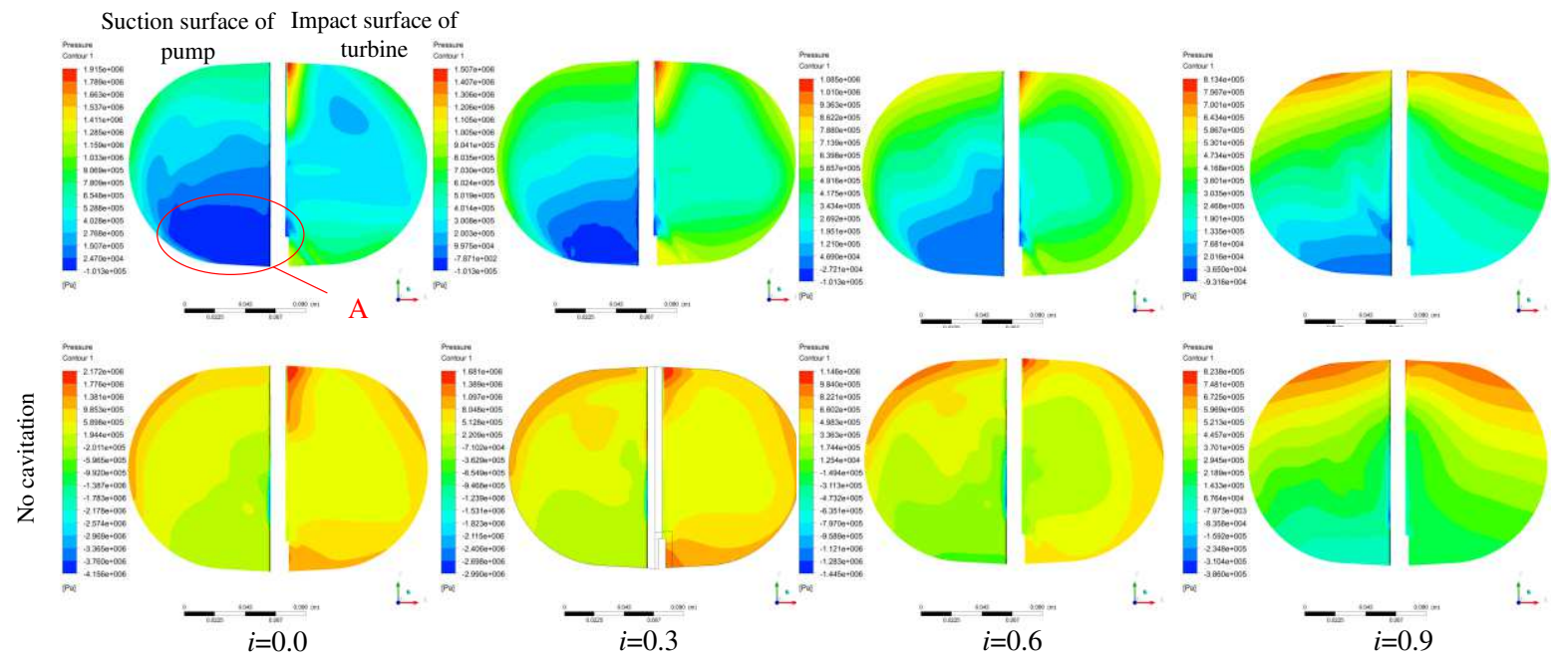

(a) Suction surface of pump and impact surface of turbine

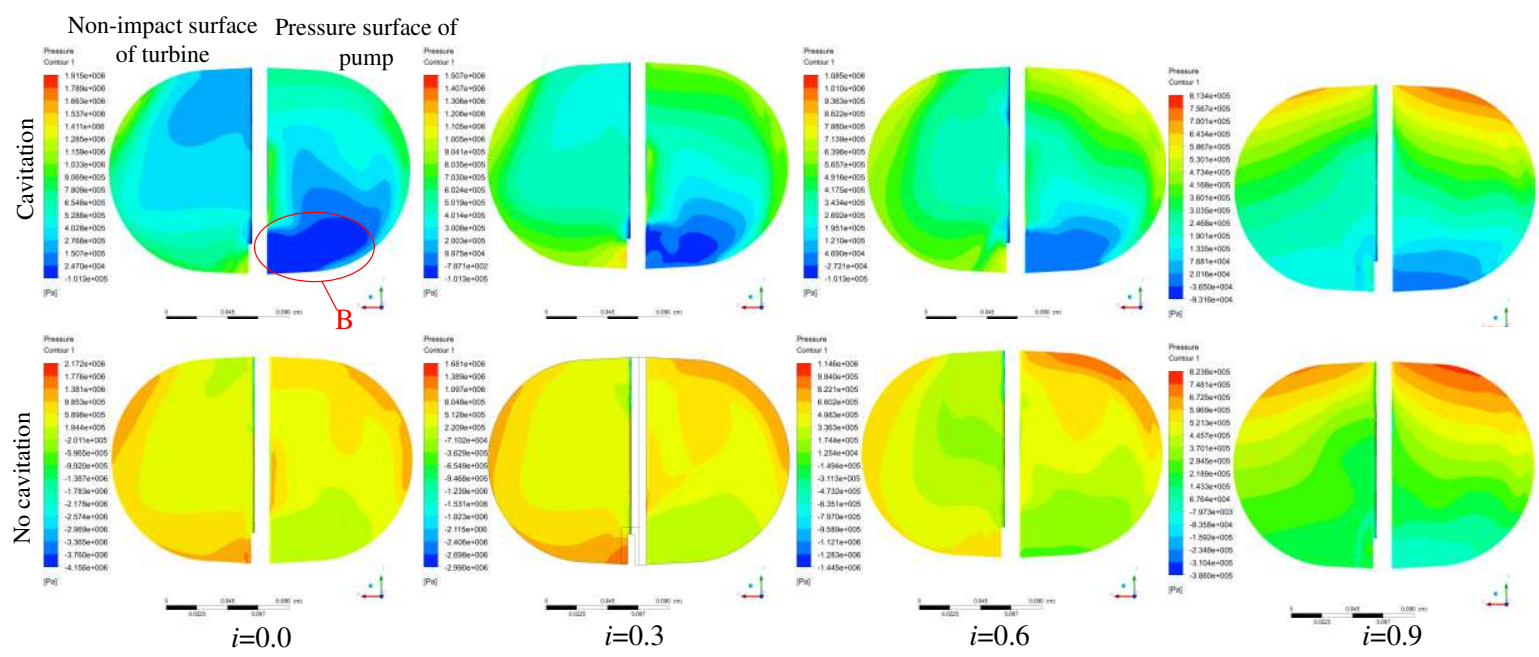

(b) Nonimpact surface of turbine and pressure surface of pump

Figure 10. Comparison of blade pressure distribution

\subsection{Characteristics of transient cavitation}

\subsubsection{Cavitation evolution}

According to the distribution law of cavitation bubbles, the bubbles are mainly generated in the pump flow field. To analyze the distribution pattern and evolution law of the cavitation field in the pump flow field, a speed ratio of 0.6 was considered as an example to analyze the volume rate distribution of cavitation in different development stages.

Because the flow field in the fluid coupling is complex and three-dimensional, the cavitation bubble movement in the flow field is also complex and three-dimensional. Figure 11 shows the development of the cavitation bubble characterized by the $90 \%$ steam volume rate isosurface. The figure shows that the evolution of cavitation bubbles can be divided into four stages. In Stage 1, the banded bubble is born around the tip on the suction surface side of the pump blade; this bubble follows the steam in the cavitation bubble. Cloudy bubbles form in the accumulation of phases. In Stage 2, cavitation bubbles always adhere to the surface of the blades. As the bubbles leave the blades, some bubbles enter the flow channel and gradually form ellipsoidal bubbles. In Stage 4, when the volume of ellipsoidal bubbles increases and reaches a certain level, they break away from the surface of the blade. They then enter the flow channel and burst after covering a certain distance. Some steam condenses, and the remaining gas continues to move in the flow field, forming broken bubbles with irregular shapes and sizes and moving toward the inner ring of the pump wheel. Eventually, as cavitation continues to 
accumulate, a vapor concentration area is formed.

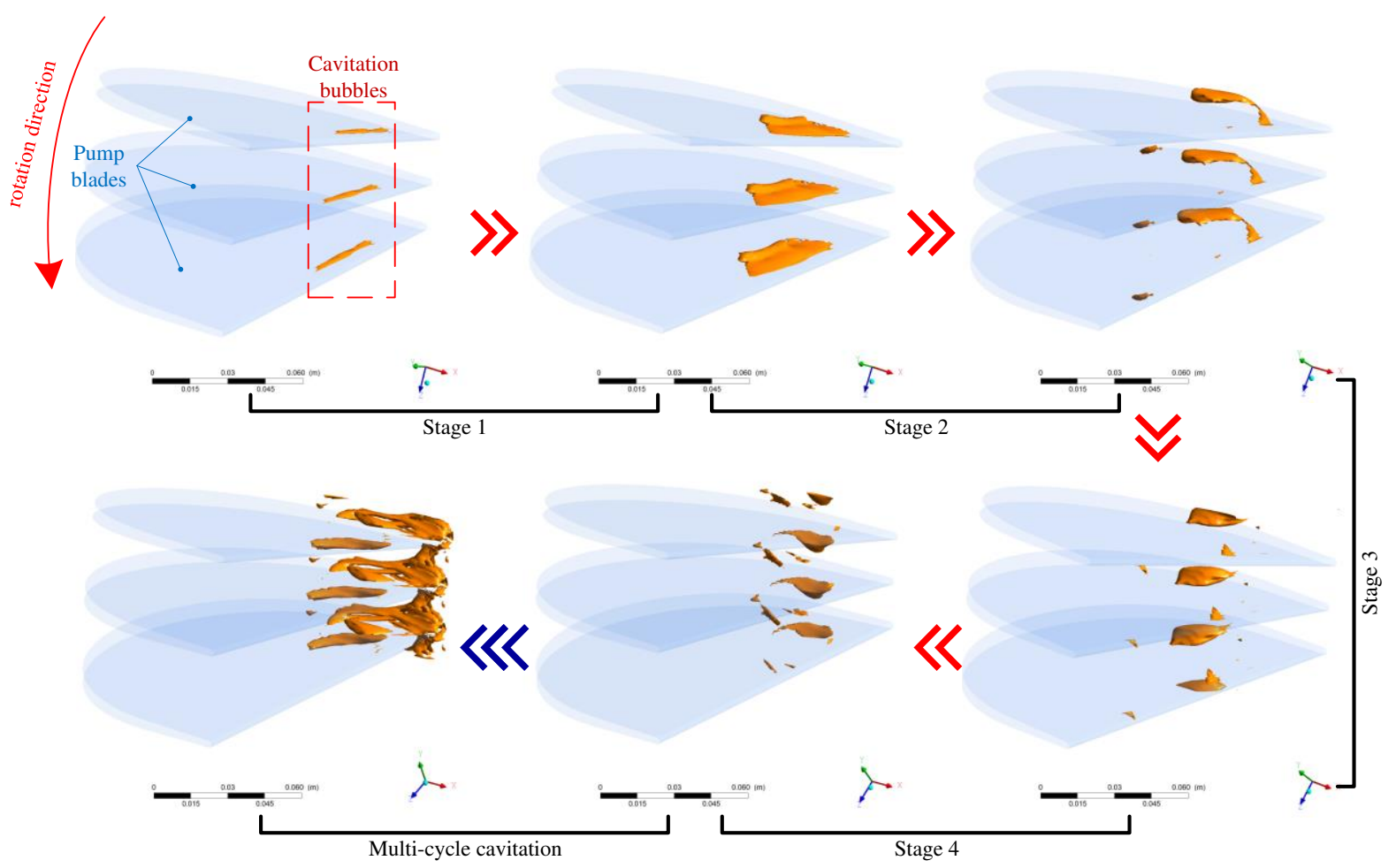

Figure 11. Evolution of cavitation bubbles

\subsubsection{Cavitation mechanism}

To obtain the volume rate, pressure, and speed distribution data of the cavitation observed near the blade tip of the pump wheel, located near the inner ring, at a speed ratio of 0.6 , a circular data analysis cross section with a diameter of $\mathrm{d}=180 \mathrm{~mm}$ was established, as shown in Figure 12.

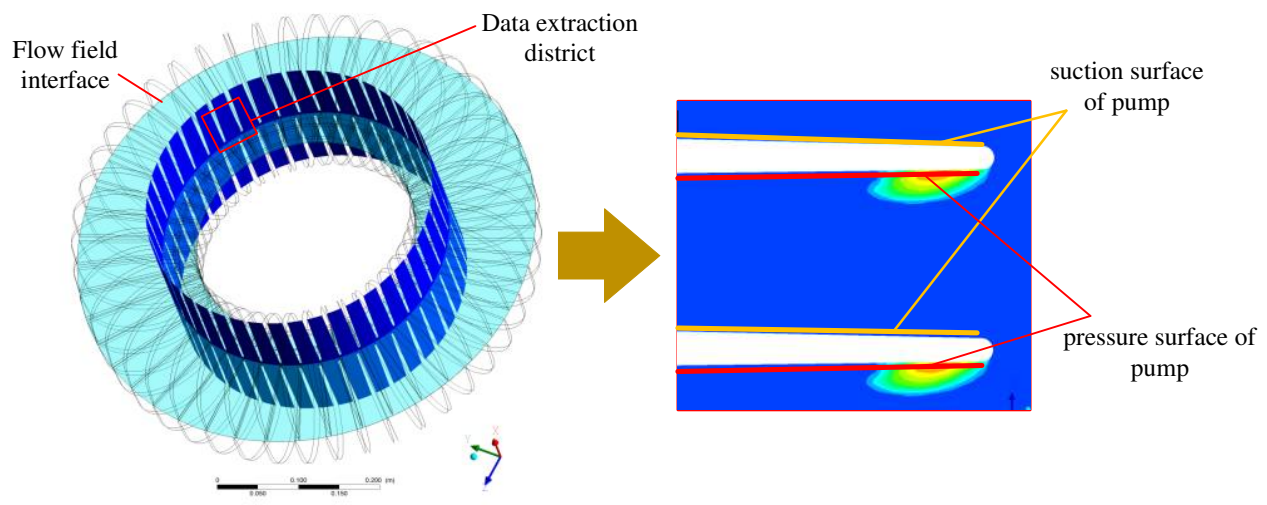

Figure 12. Schematic of cross-sectional position

Figure 13 shows the distribution of the steam volume fraction at the cross section. The evolution of cavitation from birth, growth, separation, and disintegration is evident. According to the transient changes in cross-sectional pressure and velocity, combined with the volume fraction distribution characteristics, part of the high-speed water from the turbine inner ring outlet enters the pump wheel and hits the blade tip; the flow rate then decreases rapidly and a local high pressure forms at the blade tip area. After passing through the tip area, the flow is affected by the local high pressure. Simultaneously, this flow is driven by other incoming flows to form a high-speed jet close to the blade surface as well as an angle with the surface. Therefore, on the pressure surface side of the impeller blades, a low-pressure region, wherein the pressure is below the vapor pressure, is formed near the tip of the blade; a severe cavitation phenomenon occurs in this region. As the cavitation bubble grows, the flow into the pump wheel is hindered by the 
bubble, and the jet angle increases. When the growth of cavitation is large, reverse flow can be found near the blade wall, and strong vortices are observed in the corresponding areas. This causes the internal pressure to decrease and promotes the formation of bubbles. As the cavitation bubble moves toward the inner circle of the circulation circle and breaks up, the jet angle decreases and promotes the birth of new cavitation bubbles.

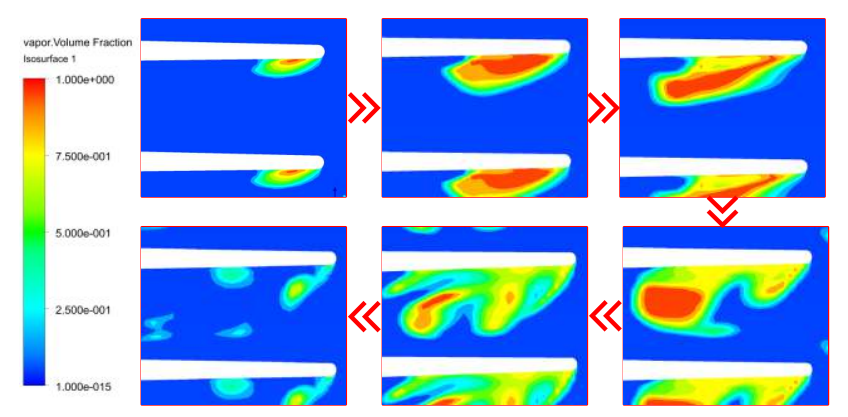

Figure 13. Distribution of steam volume fraction in the gap of pump impeller

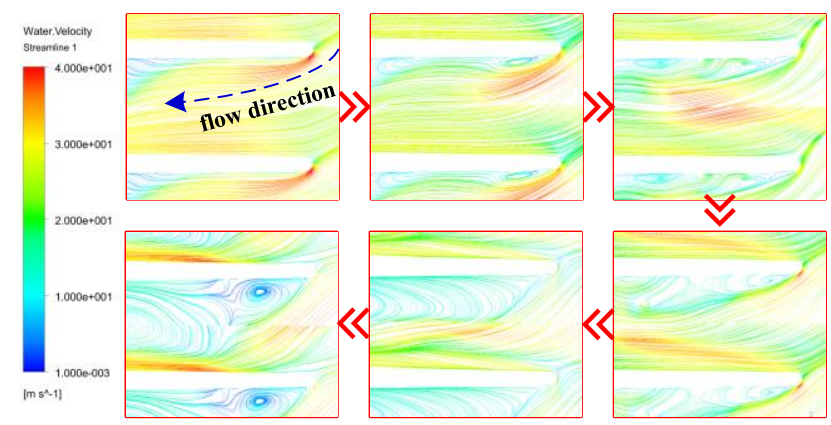

Figure 14. Distribution of water speed streamline in the gap of pump impeller

The pressure distribution in Figure 15 shows that, owing to the increase in the jet angle and the appearance of strong vortices near the blade, the range of the low-pressure area near the tip area of the blade pressure surface becomes large, which promotes the growth of cavitation. As the cavitation bubble grows further, under the influence of the bubble surface tension and the surrounding high-pressure water flow, the shape of the cavitation bubble gradually becomes irregular. As the bubble volume increases, the surface tension is insufficient to maintain the growth of the bubble, the bubble ruptures under the surrounding high pressure, and a small range of low-pressure fragmented bubble areas and new cavitation bubble birth areas form in the flow channel.

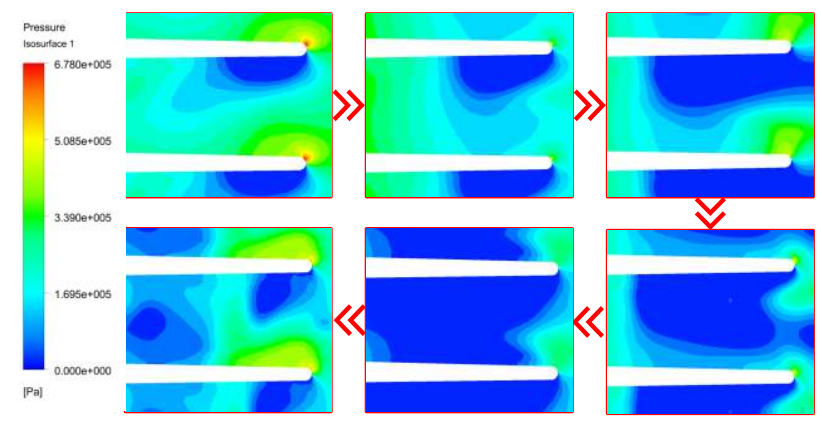

Figure 15. Distribution of water pressure in the gap of pump impeller

\subsection{Torque characteristics}

Figure 16 shows a characteristic diagram of torque transmission in a fluid coupling considering cavitation and noncavitation. Without cavitation computation, the overall output torque tends to decrease. As the speed ratio increases, the rate of decline continues to increase. The overall trend remains unchanged when the cavitation model is considered. Further, the transmission torque under cavitation is lower than that under noncavitation.

At low speed ratios, owing to the large rotational speed difference between the pump and turbine, the water-liquid circulation speed was rapid, and the cavitation phenomenon was severe. At this time, the torque transmission 
characteristic also severely deteriorated, and the output torque dropped significantly. As the speed ratio increased, the degree of cavitation in the flow field continued to decrease. At a speed ratio of approximately 0.9 , cavitation had little effect on the flow state. Therefore, the occurrence of the cavitation phenomenon considerably affected the overload starting and working ability of the coupling. This phenomenon had relatively little influence on the torque transmission ability under rated working conditions.

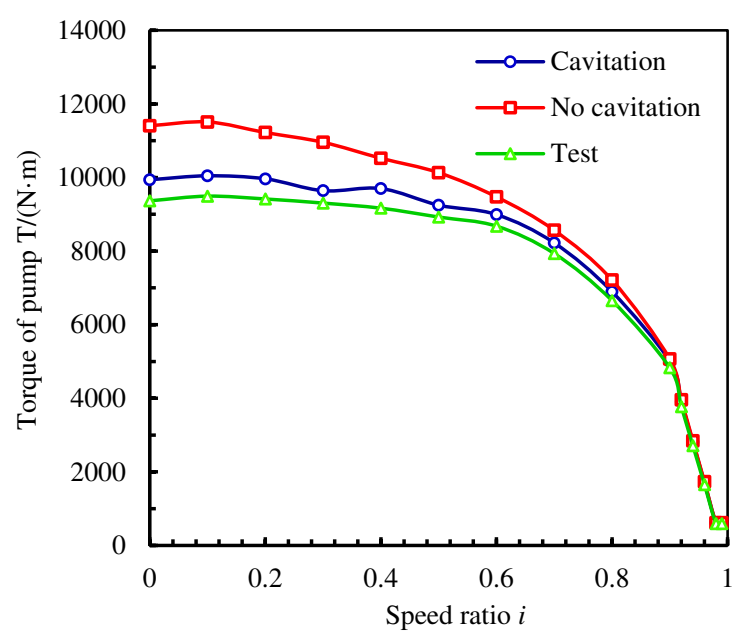

Figure 16. Transmission torque of flow field in impeller

To analyze the degree of influence of cavitation on the torque transmission characteristics accurately, $P_{\mathrm{r}}$ was defined as the torque forecast correction ratio, $T_{\mathrm{N}-\mathrm{C}}$ as the torque computational result without considering the cavitation, $T_{\mathrm{C}}$ as the torque computational result considering the cavitation, and $\Phi_{\mathrm{T}}$ as the characteristic difference.

The characteristic difference is

$$
\Phi_{\mathrm{T}}=\mathrm{T}_{\mathrm{N}-\mathrm{C}}-\mathrm{T}_{\mathrm{C}}
$$

The torque characteristic prediction correction is

$$
\mathrm{P}_{\mathrm{r}}=\left(\Phi_{\mathrm{T}}\right) / \mathrm{T}_{\mathrm{C}}
$$

A comparative analysis of the correction of the torque transfer value of the flow field at different speed ratios is shown in Figure 14. The $P_{\mathrm{r}}$ is affected by the amount of cavitation vapor accumulation and the degree of cavitation occurrence, and the overall trend is a downward trend as $S R$ increases. At $i=0, P_{\mathrm{r}}$ and $\Phi_{\mathrm{T}}$ reach the maximum. At this time, the characteristic difference is $1468.35 \mathrm{~N} \cdot \mathrm{m}$, and the correction ratio is $12.85 \%$. At a speed ratio of 0.99 , because the degree of cavitation is the lowest at this time, the correction factor is $0.32 \%$.

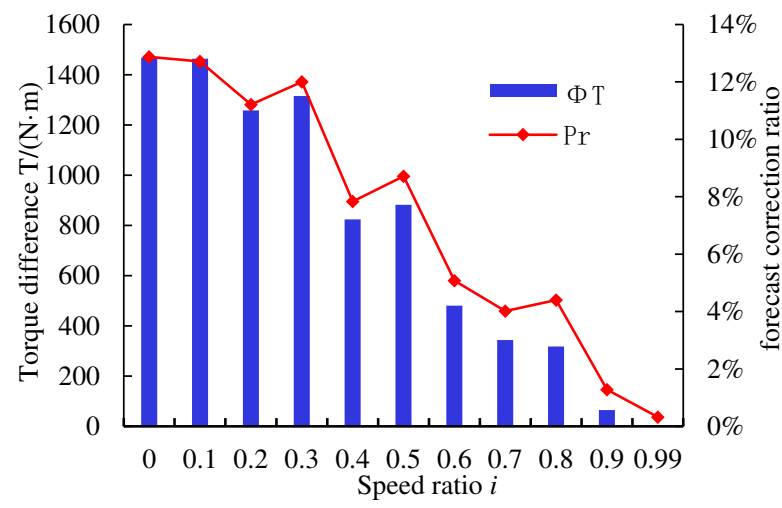

Figure 14. Torque correction distribution of cavitation model 


\section{Conclusions}

In this study, CFD technology and experiments were used to investigate the unsteady flow field affected by the cavitation characteristics of fluid coupling. Based on the numerical simulation data, the cavitation distribution, evolution characteristics, and their effects on the torque transmission characteristics were analyzed. The study clarified the following:

(1) The steady-state analysis results demonstrate that the severity of cavitation in the internal flow field of the coupling decreases with increasing SR, and the generated steam mainly accumulates at the inner ring of the pump wheel. The formation of a stable steam accumulation area reduces the circulation velocity and flow state of the flow field. Compared with the pressure distribution gradient obtained in the region not affected by cavitation, that on the blade surface affected by cavitation is larger, forming a low-pressure region near the inner ring.

(2) Transient cavitation simulation demonstrates that cavitation bubbles are generated near the tip of the blade pressure surface of the internal flow field. Affected by the flow characteristics of water, the evolution process has four stages: birth, growth, separation, and disintegration. This is a periodic cyclic process. The generated steam is finally concentrated inside the circulation circle of the pump wheel. The flow velocity and pressure at the blade surface are both reduced.

(3) An analysis of the torque transmission characteristics revealed that the torque drop is considerably affected by severe cavitation at a low speed ratio. The computation results demonstrate that the introduction of the cavitation calculation model can improve the accuracy of torque prediction by approximately $13 \%$ under a low speed ratio. The effect of cavitation is smaller at high speeds.

(4) The unstable cavitation process increases the risk of vibration, noise, and erosion and reduces the transmission capacity of the coupling. Therefore, when designing the fluid coupling, particularly from the viewpoint of high-power hydrodynamic coupling, the cavitation effect should be considered.

\section{Authors' contributions}

The author' contributions are as follows: Hongwei Cui wrote the manuscript; Jiahua Zhang and Guoqiang Wang assisted with sampling and laboratory analyses. All authors read and approved the final manuscript.

\section{Author Details}

${ }^{1}$ College of Mechanical Engineering, Taiyuan University of Technology, Taiyuan 030024, China

${ }^{2}$ State Key Laboratory of Fluid Power and Mechatronic Systems, Zhejiang University, Hangzhou 310027, China;

${ }^{3}$ Shanxi Key Laboratory of Fully Mechanized Coal Mining Equipment, Taiyuan University of Technology, Taiyuan 030024, China

\section{Authors' Information}

Hongwei Cui, born in 1986, is currently an Associate Professor at Shanxi Key Laboratory of Fully Mechanized Coal Mining Equipment, Taiyuan University of Technology, China. He received his $\mathrm{PhD}$ degree from Beijing Institute of Technology, China, in 2014. His research interests include fluid power transmission and control, hydro-viscous drive and coal mine machinery.

Tel: +86-5383463715; E-mail: cuihongwei@tyut.edu.cn

Jiahua Zhang, born in 1995, is currently a master candidate at Taiyuan University of Technology, China. He received his bachelor degree from Taiyuan University of Technology, China, in 2017.

E-mail: z526677455@163.com

Guoqiang Wang, born in 1997, is currently a master candidate at Taiyuan University of Technology, China. He received his master degree from North University of China, China, in 2019.

E-mail: 15525035704@163.com

\section{Competing interests}

The authors declare no competing financial interests.

\section{Funding}

Supported by Key Project of Key Research Programs of Shanxi Province (Grant No. 03012015002). supported by Open Foundation of the State Key Laboratory of Fluid Power and Mechatronic Systems. (Grant No. GZKF-201914)

\section{References}

[1] ZHANG Jia-hua, CUI Hong-wei, WANG Teng, et al. Two-phase circulation characteristics prediction of variable speed hydrodynamic 
coupling[J]. Chinese Hydraulics \& Pneumatics, 2020(04): 73-81. (in Chinese)

[2] YAN Qing-dong, TAN Lu, WEI Wei, et al. Thrust Load with Different Balance Holes Pattern of Turbine Hub in a Hydrodynamic Torque Converter[J]. Transactions of Beijing Institute of Technology, 2019, 39(1): 7-13. (in Chinese)

[3] LIU Chun-bao, LI Jing, XU Zhi-xuan, et al. Scale-resolving Simulation of Thermal Flow and Accurate Performance Prediction in Hydrodynamic Torque Converter[J]. Journal of Mechanical Engineering, 2018, 54(18): 146-153. (in Chinese)

[4] WEI Wei, LI Shuang-shuang, AN Yuan-yuan, et al. Determining Method for Spoilers Operating Condition at Low Oil Charging Ratio in Hydrodynamic Retarder[J], Transactions of Beijing Institute of Technology, 2017, 37(7): 672-676. (in Chinese)

[5] MA Wen-xing, WANG Wen-bo, LIU Chun-bao. Design and Analysis for a Torque Converter with Adjustable Axial-flow Guide Vane[J]. Chinese Hydraulics \& Pneumatics, 2015(12): 1-6. (in Chinese)

[6] C.L. Anderson, L. Zeng, P.O. Sweger, A. Narain. Experimental Investigation of Cavitation Signatures in an Automotive Torque Converter Using a Microwave Telemetry Technique[J]. International Journal of Rotating Machinery, 2003, 9: 403-410.

[7] Cheng Liu; Wei Wei; Qingdong Yan; Brian K. Weaver; Houston G Wood, Influence of Stator Blade Geometry on Torque Converter Cavitation, ASME Journal of Fluids Engineering, 2018. 4, 140(4): 0411021-04110210

[8] Liu C, Guo M, Yan Q, et al. Numerical Investigation on the Transient Cavitating Flow Inside a Torque Converter[C]. international conference on fluid power and mechatronics, 2019.

[9] Robinette D. Detecting and Predicting the Onset of Cavitation in Automotive Torque Converters[D]. Michigan: Michigan Technological University, 2007.

[10] Robinette D, Schweitzer J M, Maddock D G, et al. Predicting the Onset of Cavitation in Automotive Torque Converters-Part I: Designs with Geometric Similitude[J]. International Journal of Rotating Machinery, 2008: 1-8.

[11] Robinette D, Schweitzer J M, Maddock D G, et al. Predicting the Onset of Cavitation in Automotive Torque Converters-Part II: A Generalized Model[J]. International Journal of Rotating Machinery, 2008: 1-8.

[12] Dong Y, Korivi V, Attibele P, et al. Torque converter CFD engineering part 2: performance improvement through core leakage flow and cavitation control. SAE paper 2002-01-0884, 2002.

[13] ZHAO Li-li, DONG Zhiqiang, LIAN Jin-yi et al, Analysis of Bubble Breakup Motion for Hydrodynamic Torque Converter[J]. Hydraulics Pneumatics \& Seals, 2016, 9: 1-4. (in Chinese)

[14] Watanabe, Hisashi, Kazunori Yoshida, Masatoshi Yamada. Flow Visualization and Measurement in the Stator of a Torque Converter[J]. JSAE Review, 1996, 17(1): 25-30.

[15] Watanabe, Hisashi, Tesuo Karahashi,Masahiro Kojima. Flow Visualization and Measurement of Torque Converter Stator Blades Using a Laser Sheet Lighting Method and a Laser Doppler Velocimeter[C]. SAE Technical Paper 970680.

[16] Watanabe, Masato, Kazumichi Sasaki, Koichi Miyamoto. Toyota's New Six-Speed Automatic Transmission AB60E for RWD Vehicles[C]. SAE Technical Paper 2007-01-1098.

[17] KANG Can, MAO Ning; ZHANG GuiFeng; Highly Confined Floes and Cavitation Phenomenon in a Hydraulic Retarder[J]. Journal of Engineering Thermophysics, 2017.38(10): 2151-2158. (in Chinese)

[18] DONG Liang; XIAO Jiawei; MING Jiayi et al, Numerical simulation and experimental study on cavitation behavior of hydraulic retarder model[J]. Journal of Drainage and Irrigation Machinery Engineering, 2017, 35(01) : 1-5. (in Chinese)

[19] Cheng H Y, Bai X R, Long X P, et al. Large Eddy Simulation of the Tip-leakage Cavitating flow with an insight on how cavitation influences vorticity and turbulence[J]. Applied Mathematical Modelling, 2020: 788-809.

[20] Bai X, Cheng H, Ji B, et al. Large eddy simulation of tip leakage cavitating flow focusing on cavitation-vortex interaction with Cartesian cut-cell mesh method[J]. Journal of Hydrodynamics, 2018, 30(4): 750-753.

[21] Sun T, Wei Y, Zou L, et al. Numerical investigation on the unsteady cavitation shedding dynamics over a hydrofoil in thermo-sensitive fluid[J]. International Journal of Multiphase Flow, 2019: 82-100.

[22] M.V. Timoshevski, LL Zapryagaev, K S. Peryunin, D M Markovich Cavitation Contron on a 2D Hydrofoil through a Continuous Tangential Injection of Liquid: Experimental Study[C]. Proc. of 2016 International Conference on the Methods of Aerophysical Research (ICMAR2016) Perm, Russia, 2016: Paper No. 030026.

[23] Hur N, Kwak M, Moshfeghi M, et al. Numerical flow analyses of a two-phase hydraulic coupling[J]. Journal of Mechanical Science and Technology, 2017, 31(5): 2307-2317. 
[24] Silva M J, Lu Y, Suhnel T, et al. Autonomous planar conductivity array sensor for fast liquid distribution imaging in a fluid coupling[J]. Sensors and Actuators A-physical, 2008, 147(2): 508-515.

[25] Hur N, Moshfeghi M, Lee W, et al. Flow and performance analyses of a partially-charged water retarder[J]. Computers \& Fluids, 2016: 18-26.

[26] Wang Chao, Guo Haipeng, Zhang Lixin, He Xin. Influence of eadingedgy Suction on Hydrodynamic and Cavitation Performance of Hydrofoil[J] Journal of Ship Mechanics, 2013, 17(12): 1361-1370. (in Chinese)

[27] Liu C, Li J, Bu W, et al. Application of scale-resolving simulation to a hydraulic coupling, a hydraulic retarder, and a hydraulic torque converter[J]. Journal of Zhejiang University Science, 2018, 19(12): 904-925. 
Figures

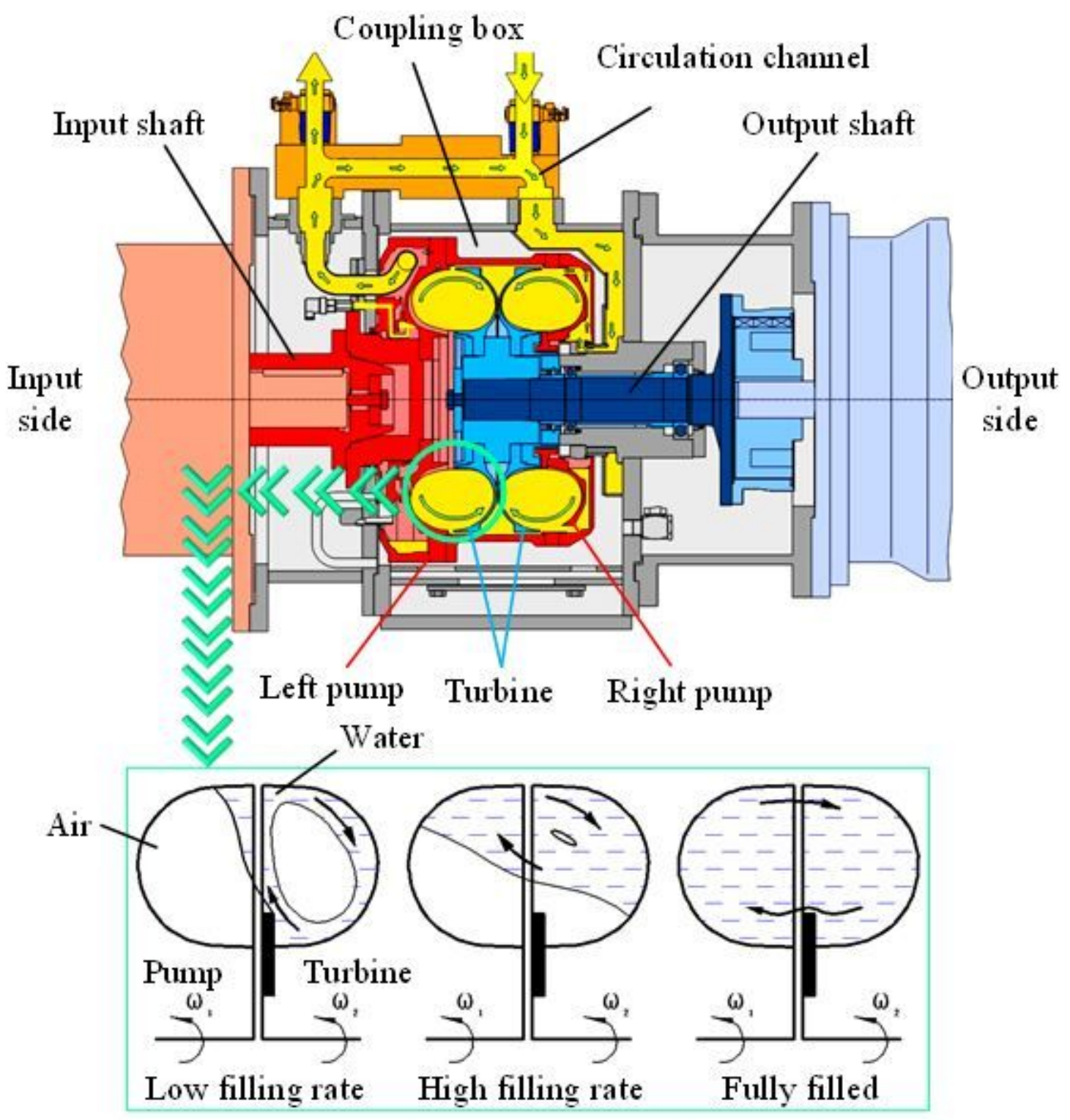

Figure 1

Structure and working principle of hydrodynamic coupling 

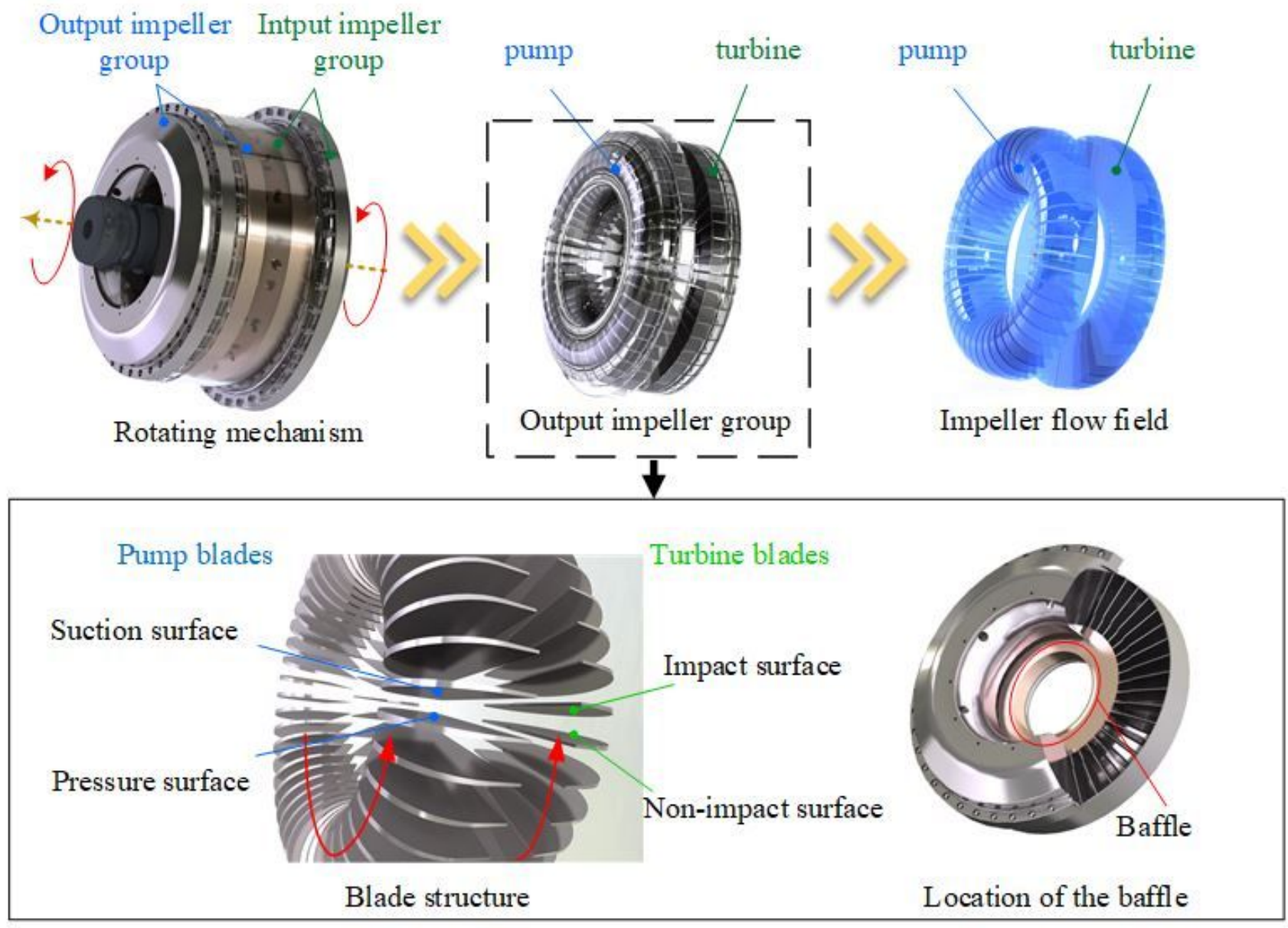

\section{Figure 2}

Hydrodynamic coupling impeller and flow field structure 


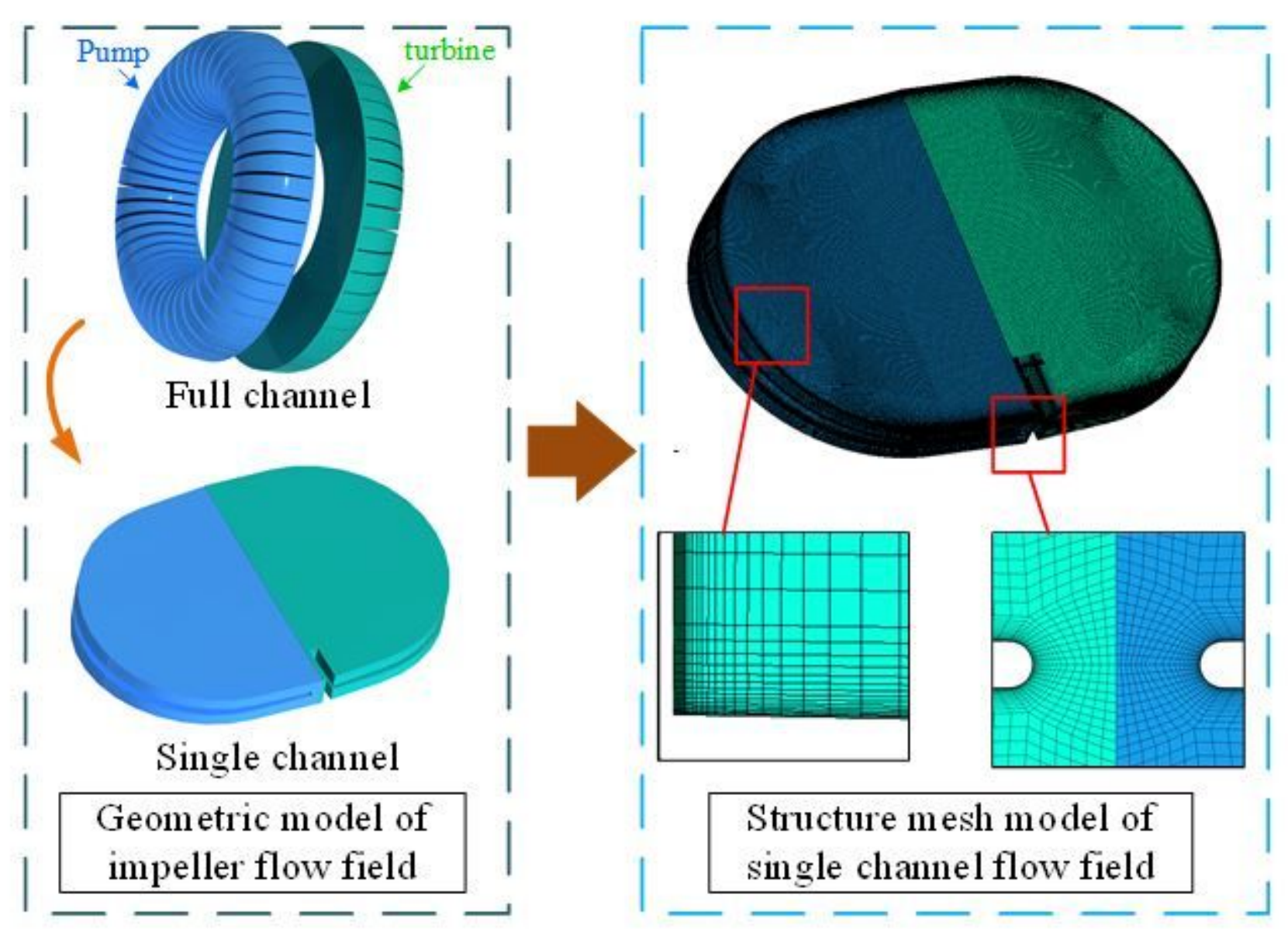

Figure 3

Single-channel structured grid construction process 


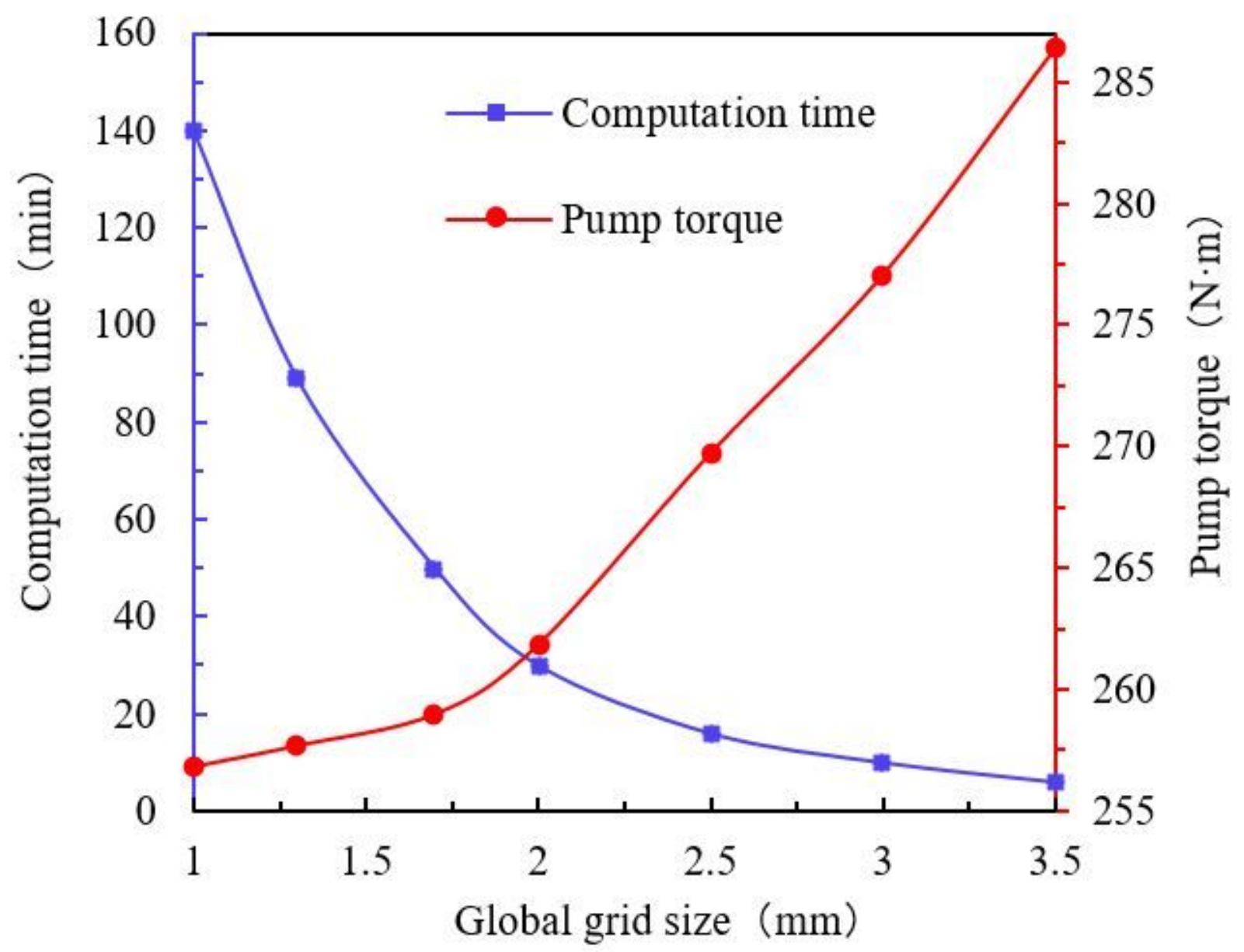

Figure 4

Analysis results of grid independence test 

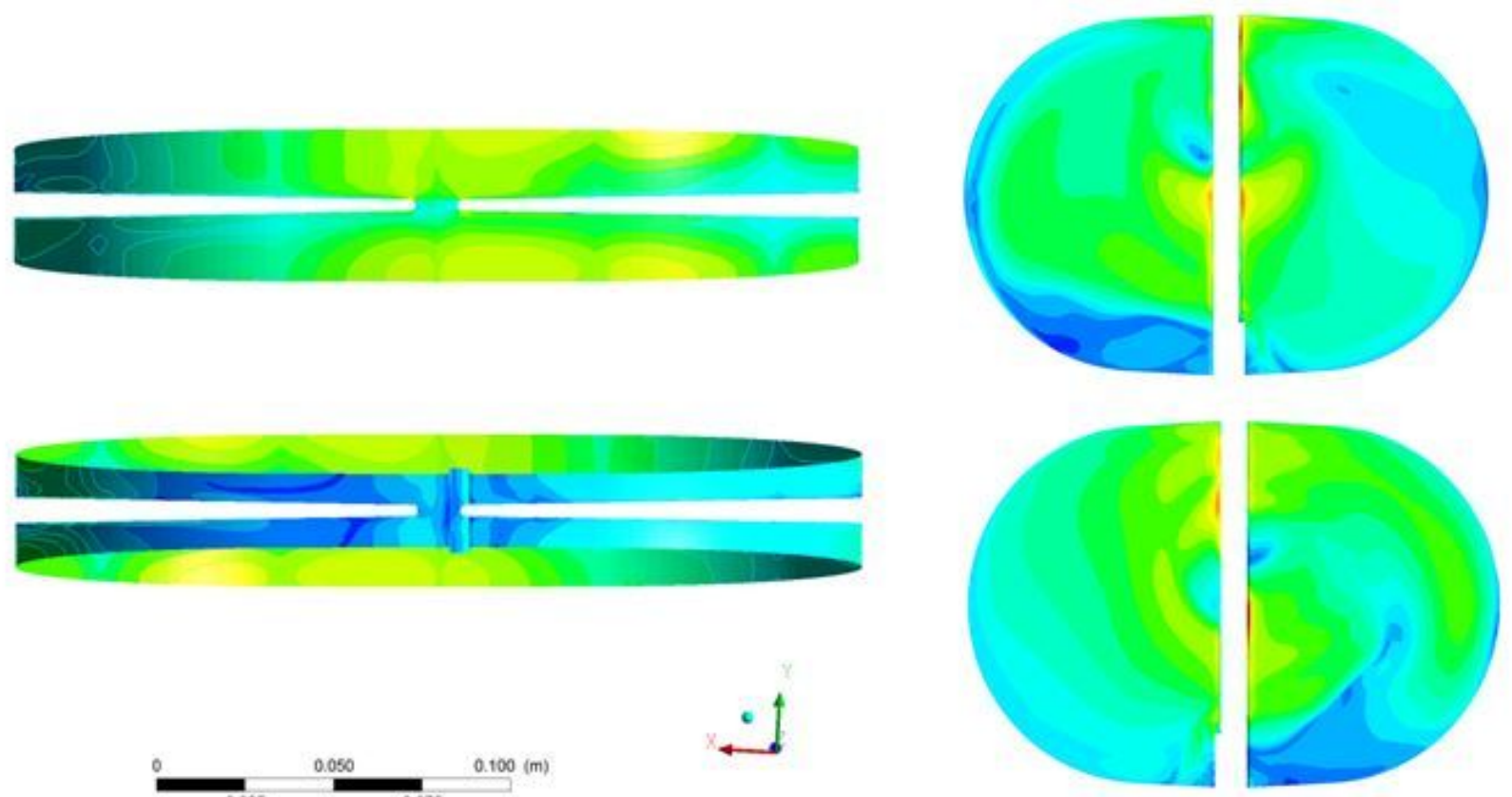

\section{Distribution of $y+$ at the wall}

\section{Distribution of $y+$ at the blade}

\section{Figure 5}

Computation result of $y+$

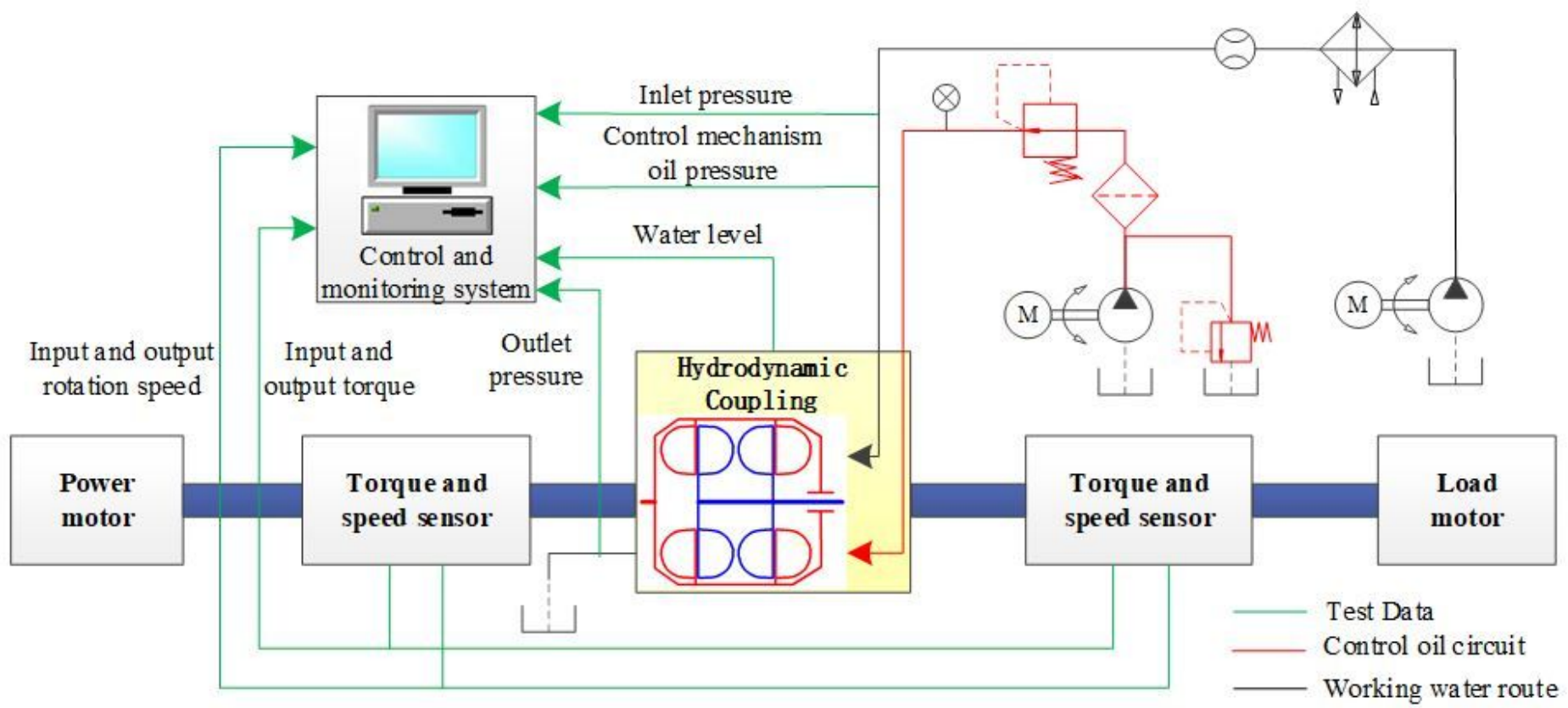

Figure 6 
Macro characteristics test plan

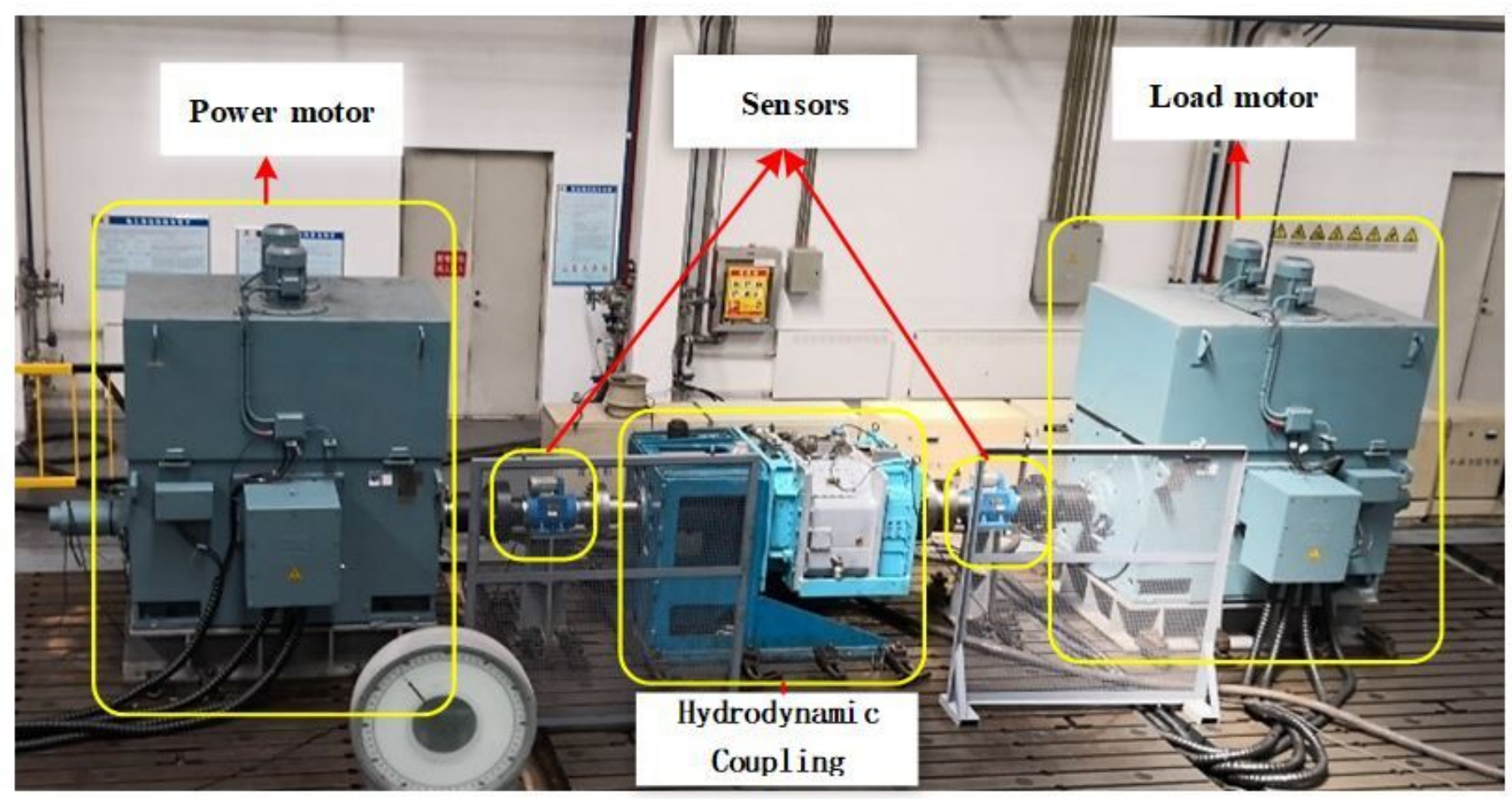

Figure 7

Macro characteristic test rig 

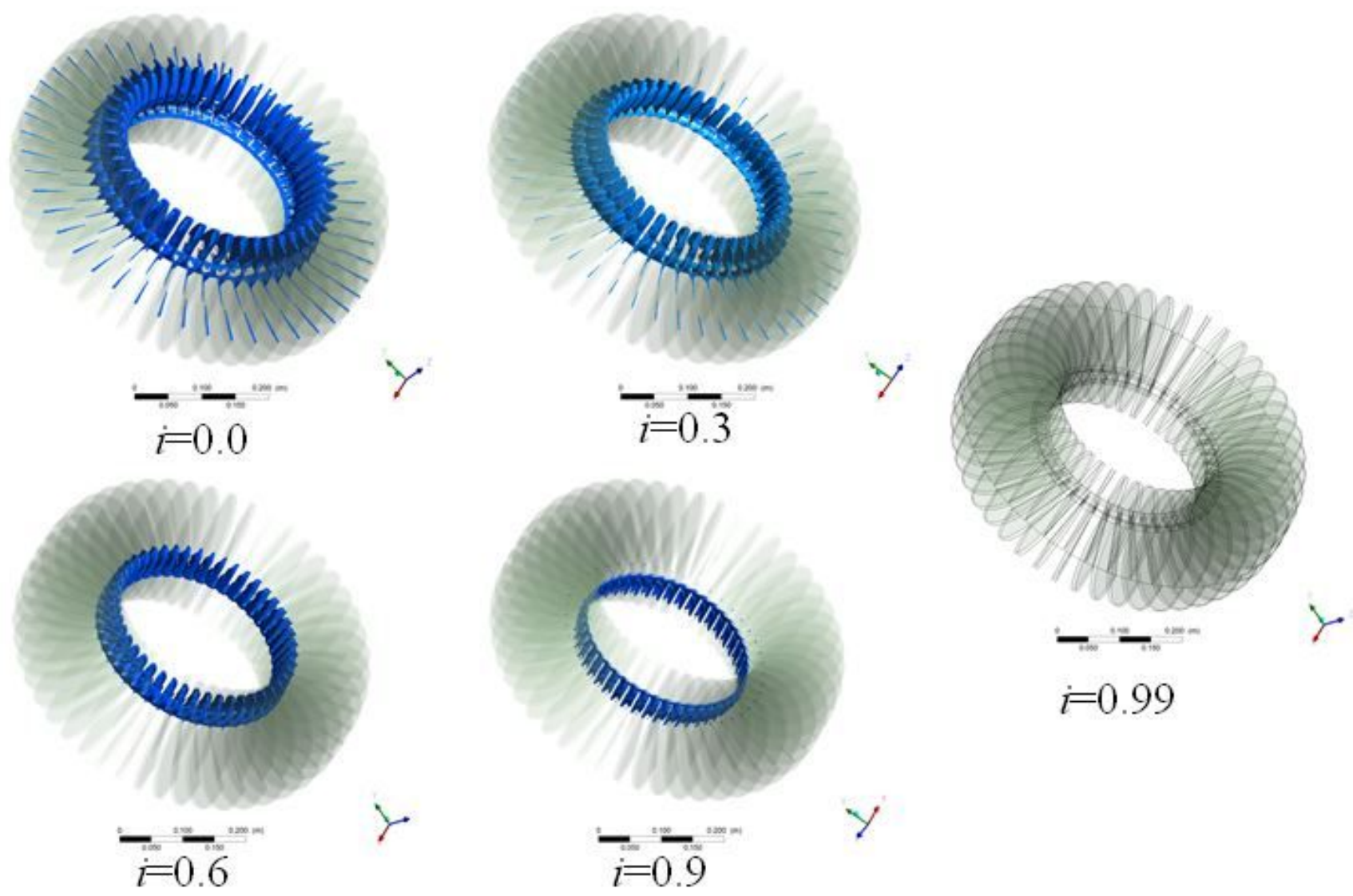

$i=0.99$

\section{Figure 8}

Steady-state cavitation distribution
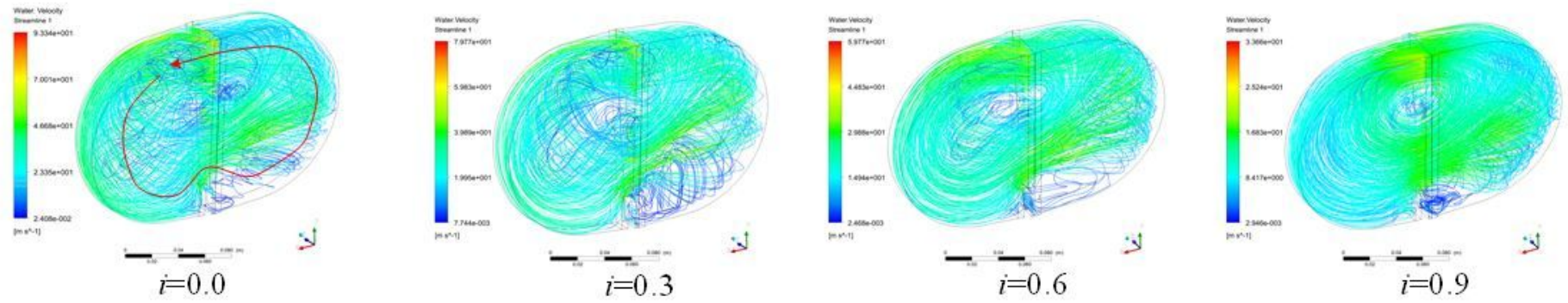

(a) Cavitation model is off
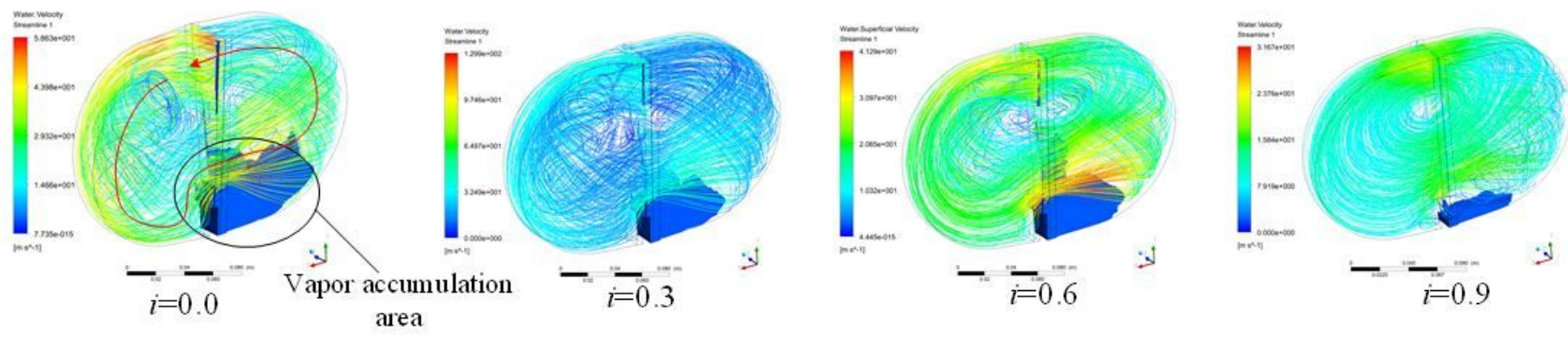

(b) Cavitation model is on 
Figure 9

Velocity streamline distribution

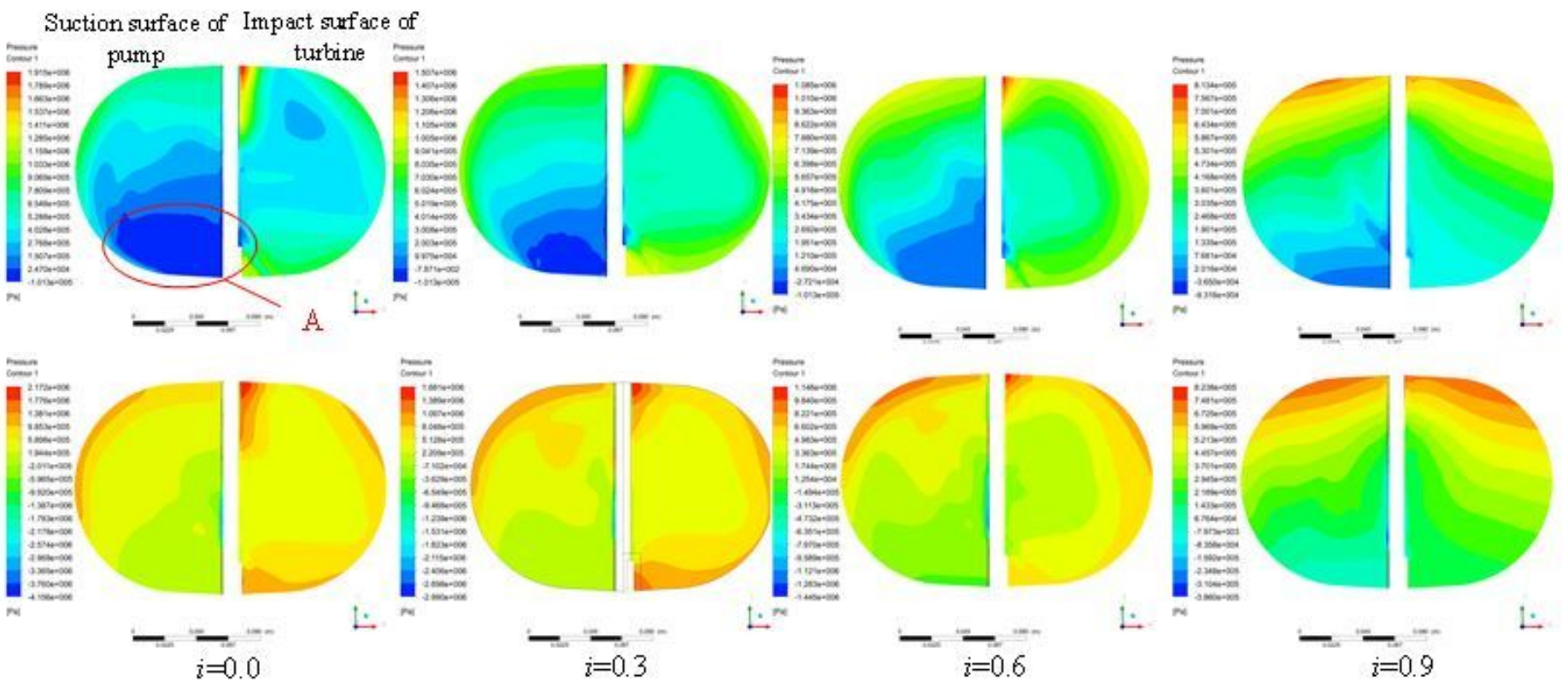

(a) Suction surface of pump and impact surface of turbine
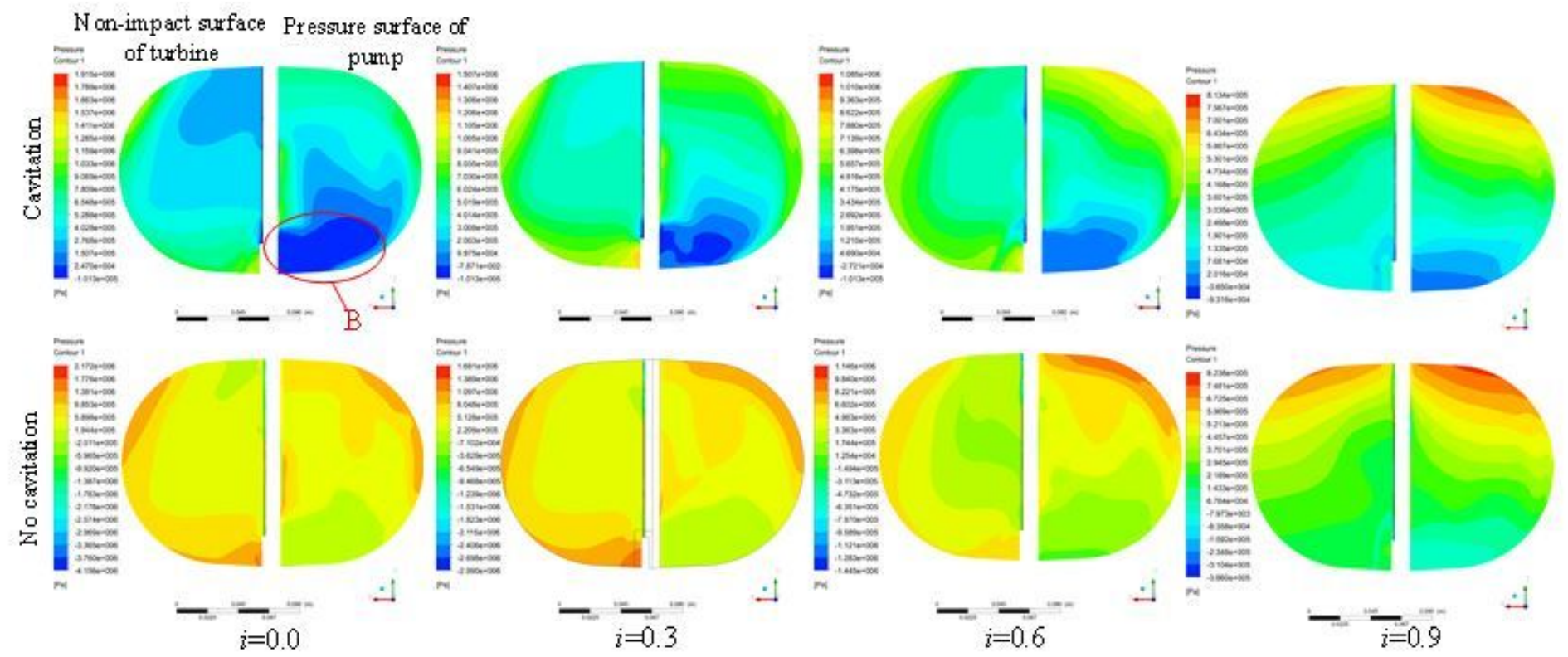

(b) Nonimpact surface of turbine and pressure surface of pump

Figure 10

Comparison of blade pressure distribution 

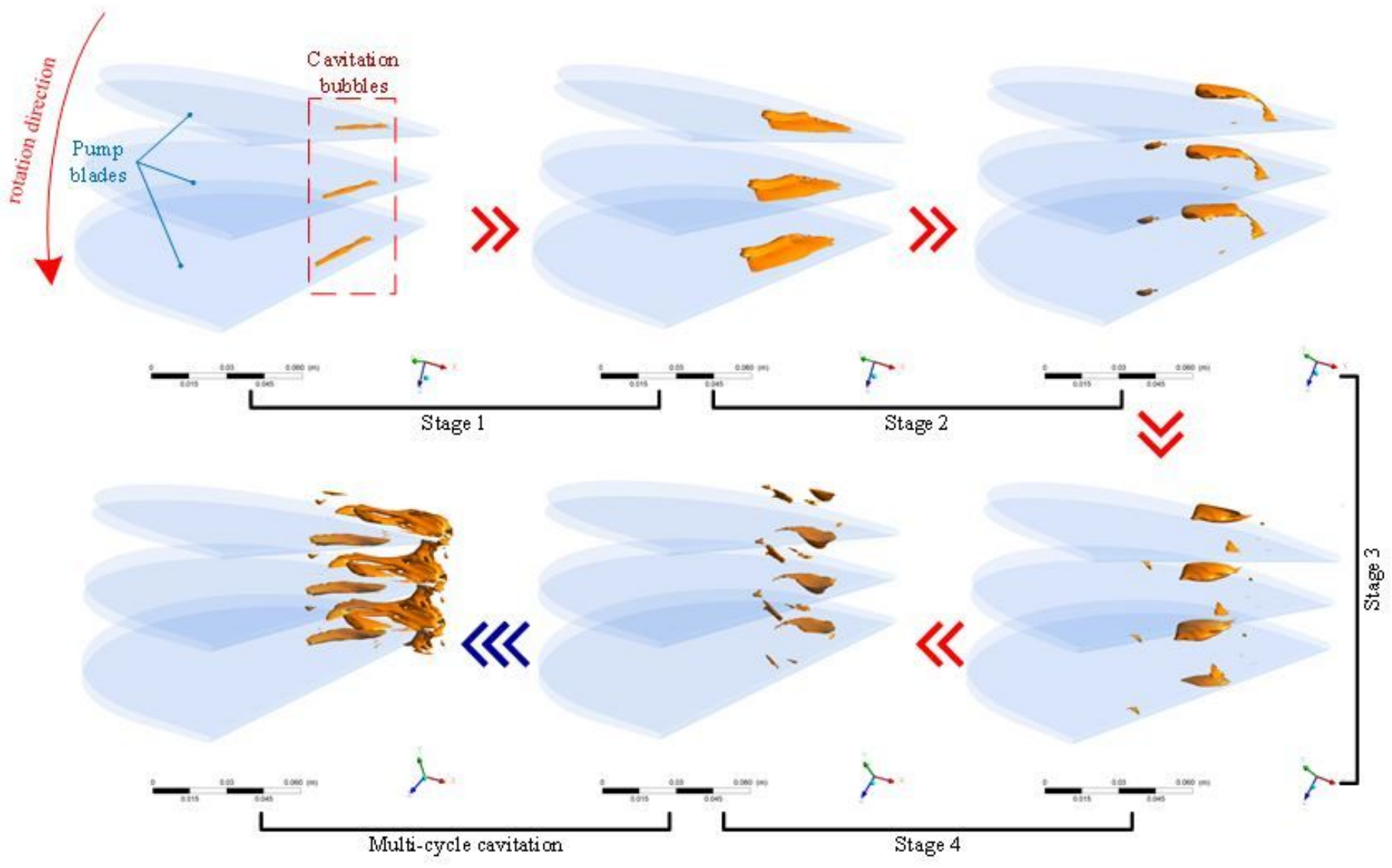

Figure 11

Evolution of cavitation bubbles

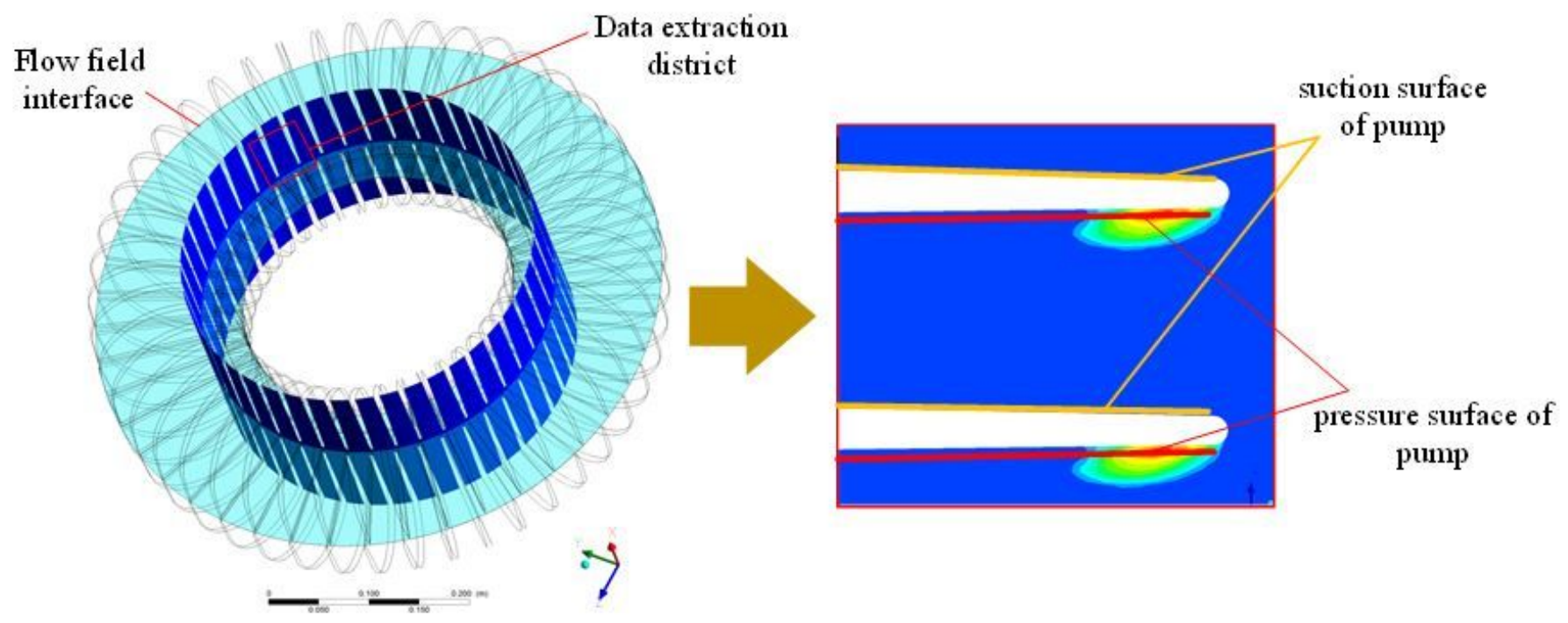

Figure 12

Schematic of cross-sectional position 


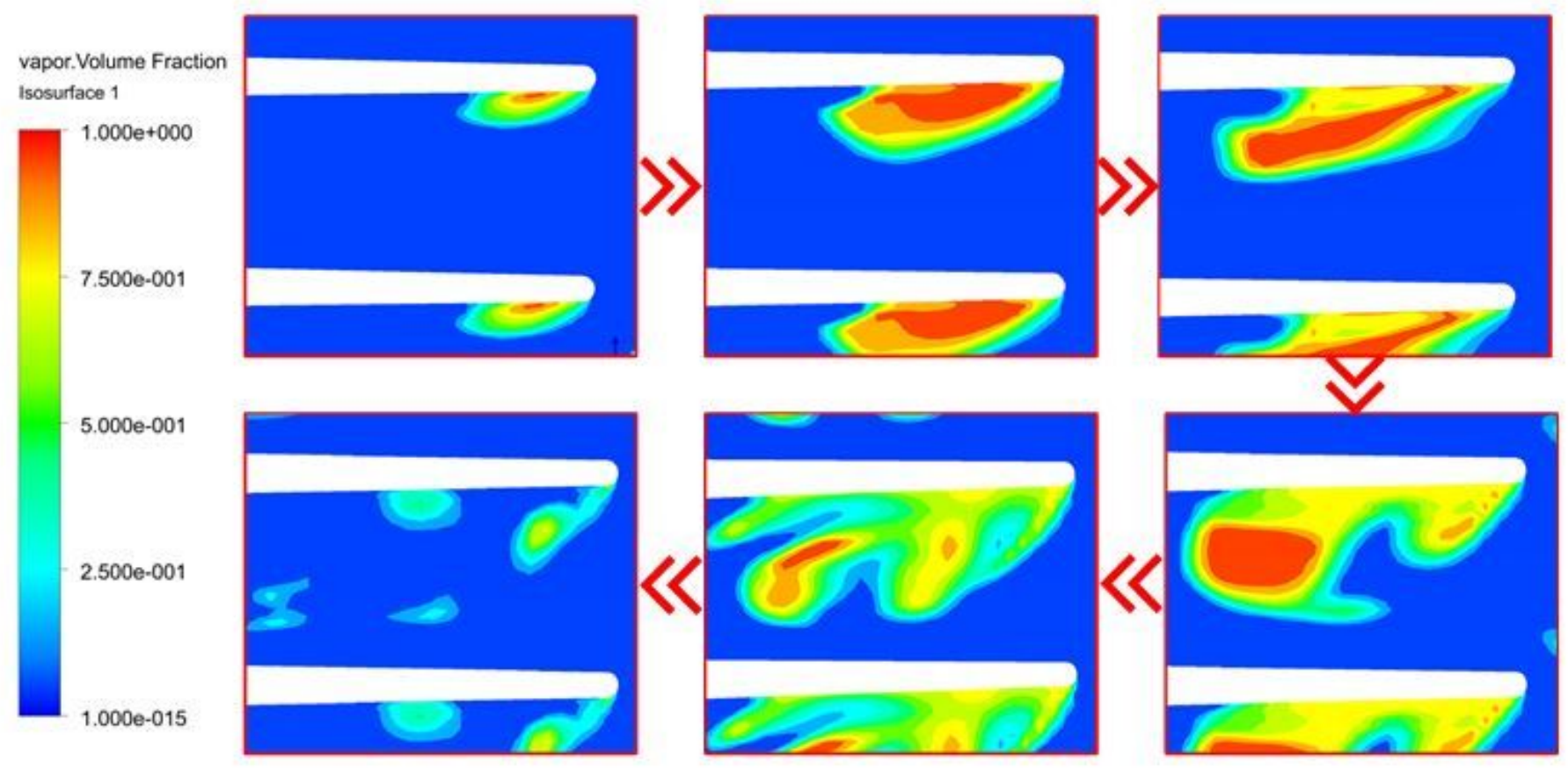

Figure 13

Distribution of steam volume fraction in the gap of pump impeller

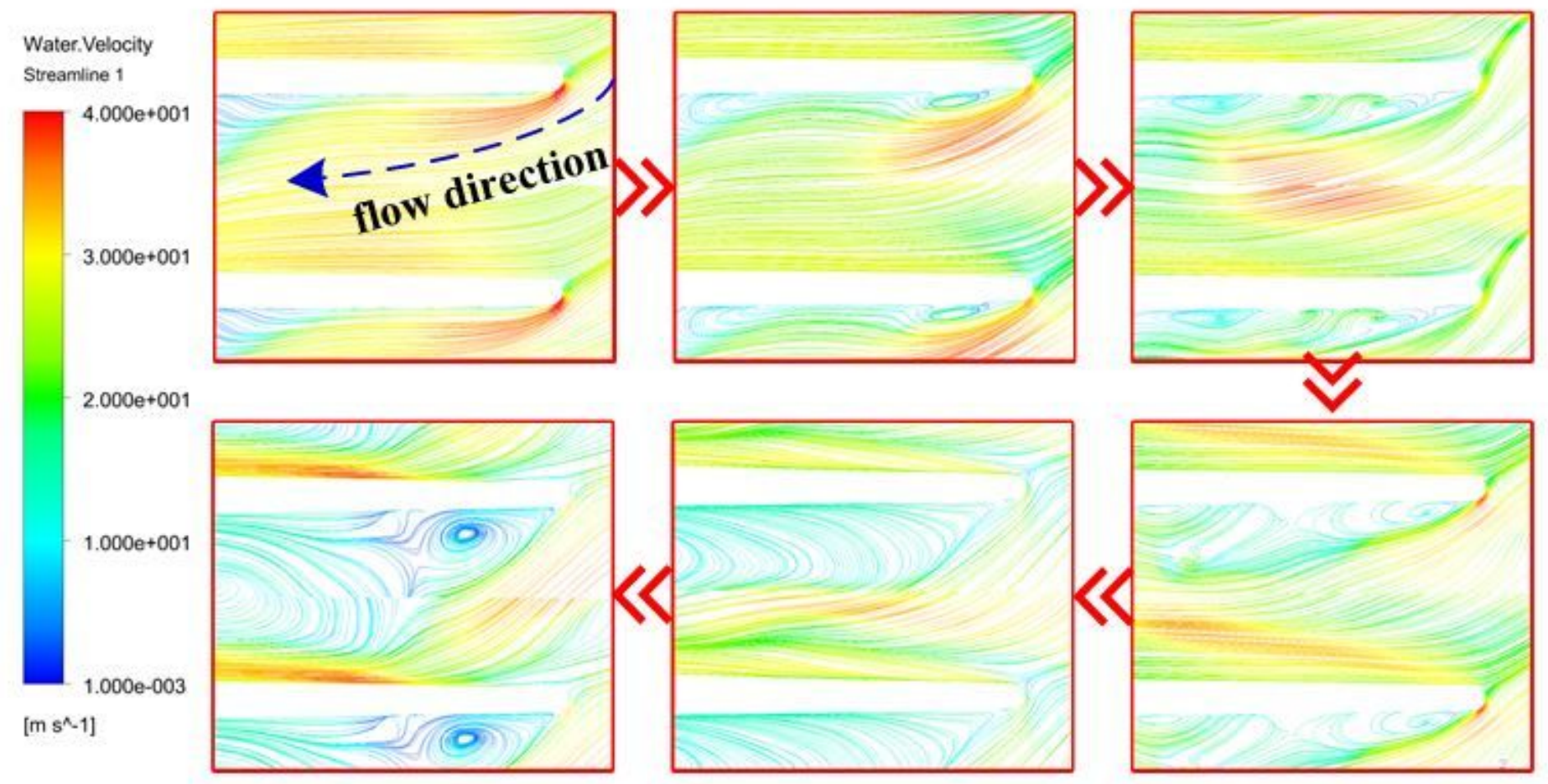

Figure 14

Distribution of water speed streamline in the gap of pump impeller 


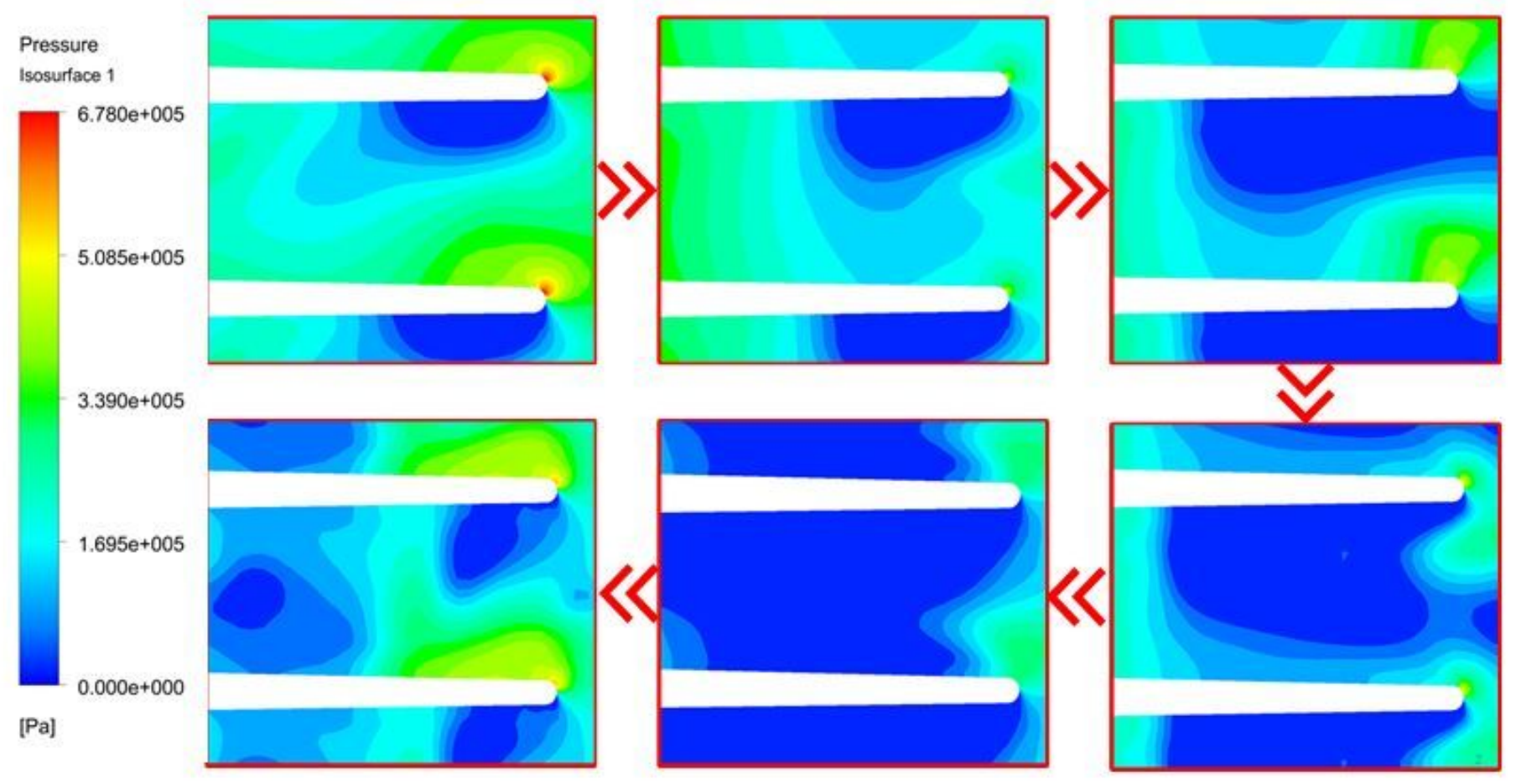

Figure 15

Distribution of water pressure in the gap of pump impeller 


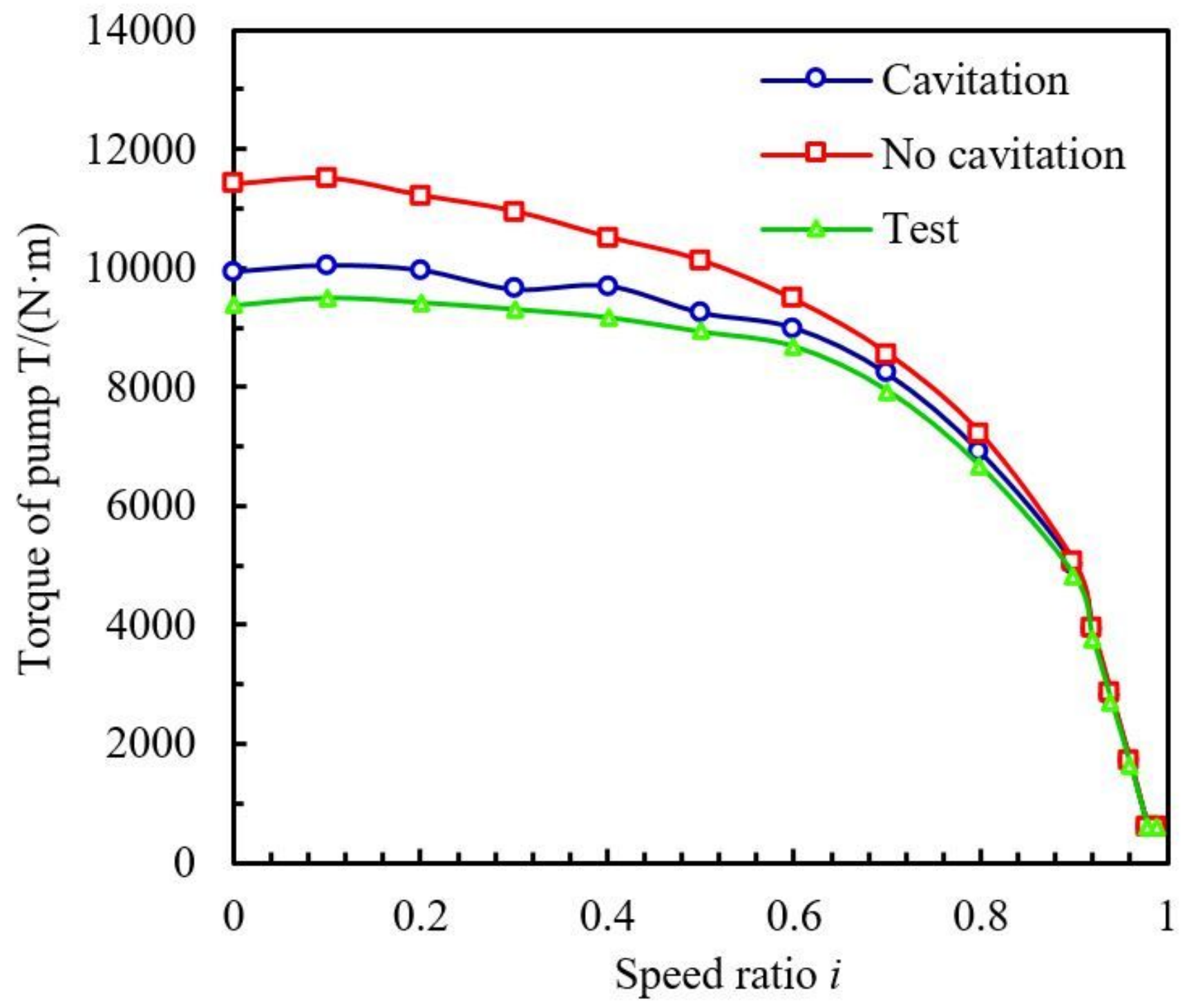

Figure 16

Transmission torque of flow field in impeller 


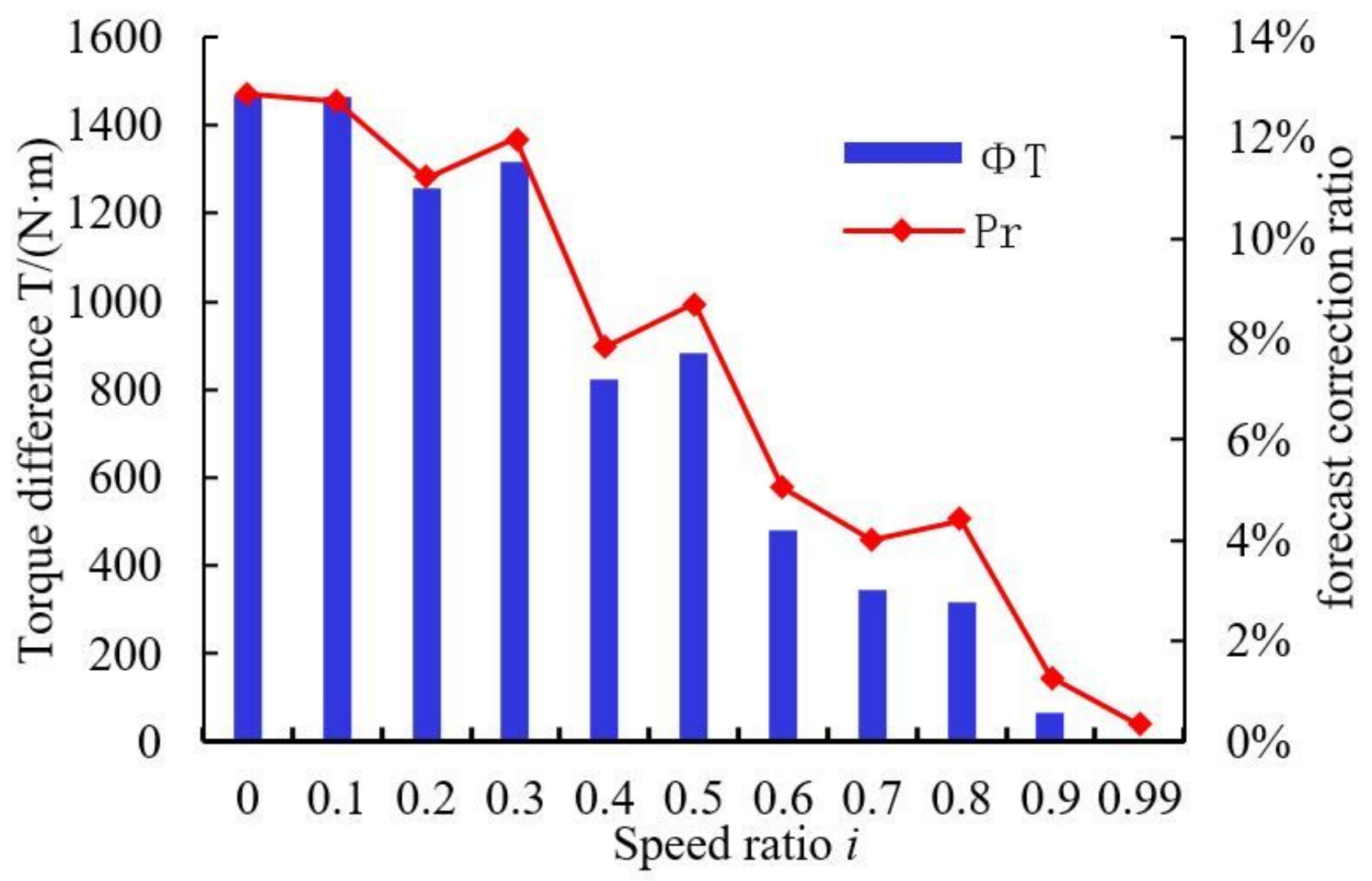

Figure 17

Torque correction distribution of cavitation model 